\title{
¿Convective Couplings with Equatorial Rossby Waves and Equatorial Kelvin Waves. Part I: Coupled Wave Structures
}

\author{
YUHI NAKAMURA ${ }^{\mathrm{a}}$ AND YUKARI N. TAKAYABU ${ }^{\mathrm{a}}$ \\ a Atmosphere and Ocean Research Institute, The University of Tokyo, Chiba, Japan
}

(Manuscript received 16 March 2021, in final form 22 October 2021)

\begin{abstract}
This study investigates precipitation amounts and apparent heat sources, which are coupled with equatorial Kelvin waves and equatorial Rossby waves, using TRMM PR level 2 data products. The synoptic structures of wave disturbances are also studied using the ERA5 dataset. We define the wave phase of equatorial waves based on FFT-filtered brightness temperature and conduct composite analyses. Rossby waves show a vertically upright structure and their upright vortices induce large-amplitude column water vapor (CWV) anomalies. Precipitation activity is almost in phase with $\mathrm{CWV}$, and thus is consistent with a moisture mode. Kelvin waves, on the other hand, indicate a nearly quadrature phase relationship between temperature and vertical velocity, like gravity wave structure. Specific humidity develops from near the surface to the middle troposphere as the Kelvin wave progresses. A clear negative CWV anomaly also does not exist despite the existence of negative precipitation anomalies. Convective activity corresponds well with its tilting structure of moisture and modulates the phase relationship between temperature and vertical motion. For both wave cases, apparent heat sources can amplify available potential energy despite the difference of coupling mechanisms of these two waves; precipitation is driven by CWV fluctuation for the Rossby wave case, and by buoyancy-based fluctuations for the Kelvin wave case. These can be observational evidence of actual coupling processes that is comparable to previous idealized studies.

SIGNIFICANCE STATEMENT: A coupling mechanism between equatorial waves and convective activity is a significant issue in tropical meteorology. While many previous idealized studies suggested some instability mechanisms, their true roles are not yet clear because detailed precipitation characteristics are not well investigated. We aim to quantify precipitation and synoptic-scale wave disturbances, and compare equatorial Rossby waves and equatorial Kelvin waves, which should have different instability coupling modes between each other, in order to shed light on a convectively coupling mechanism. We found that precipitation is actually driven by column moisture in Rossby waves and by dynamical fluctuation in Kelvin waves. Despite these competing mechanisms, similar top-heavy heating can maintain convectively coupled disturbances. Our observational results will support and improve theoretical studies.
\end{abstract}

KEYWORDS: Atmosphere; Tropics; Kelvin waves; Rossby waves; Waves, atmospheric; Satellite observations; Moisture/moisture budget; Radars/Radar observations

\section{Introduction}

Wave disturbances along the equator that propagate zonally are commonly known as equatorial waves. Matsuno (1966) theoretically derived the dispersion relation of equatorial waves and showed that there are multiple wave modes that correspond to dispersion curve branches. Studies in the 1990s demonstrated that equatorial wave disturbances couple with convective activity. Liebmann and Hendon (1990) showed that a disturbance near the international date line with a period of 4-5 days had a mixed Rossby-gravity wave structure, which clearly differs from easterly waves. Takayabu (1994) found that the spatiotemporal spectrum of cloud activity shows a dispersion pattern that corresponds to equatorial wave modes, with a significantly slower phase speed compared to stratospheric free waves. This is confirmed by

\footnotetext{
D Denotes content that is immediately available upon publication as open access.

Corresponding author: Yuhi Nakamura, yuhi_n@aori.u-tokyo.
ac.jp
}

Wheeler and Kiladis (1999) by applying a red-noise filter to the power spectral analysis. The above studies indicated a common equivalent depth among various equatorial wave modes which are relatively shallow when compared to what is expected from dry theory (e.g., Salby and Garcia 1987). These waves are known as convectively coupled equatorial waves (CCEWs) and the dynamical characteristics of CCEWs are well reviewed in Kiladis et al. (2009).

Various coupling mechanisms between equatorial waves and convective activity have been suggested. Under conditions of high correlation between lower horizontal convergence and diabatic heating due to convective activity, first baroclinic gravity waves and Kelvin waves with vertically tilted structure can amplify by synchronized upper warm anomaly and diabatic heating. This instability mechanism is known as wave instability of the second kind, or "wave-CISK" (Yamasaki 1969; Hayashi 1970; Lindzen 1974). Although this assumed correlation is generally seen in the tropics, the wave-CISK is not valid for explaining its time and spatial scales (e.g., Matthews and Lander 1999). A simple model using convective parameterization controlled by convective inhibition yields larger spatiotemporal-scale disturbances known as "stratiform instability" (Mapes 2000). The first and second baroclinic modes are associated with convective and 
stratiform modes, respectively. These two vertical normal modes allow a simple model to represent organized convective systems. Furthermore, combining these modes with midlevel moisture (Kuang 2008) yields a trimodal convective evolution as follows: shallow convection, deep convection, and organized systems with stratiform rain, which is ubiquitously observed in tropics (Johnson et al. 1999; Houze 1989). This is referred to as "moisture-stratiform instability" (Kuang 2008). First, low-level warm anomaly induces shallow cumulus and preconditioning, then deep convection become active under deeply moist condition, and stratiform rain that is in phase with upper warm anomaly can grow instability at last. Previous numerical model research (e.g., Khouider and Majda 2006, 2007, 2008; Tulich et al. 2007) also clearly showed a gravity wave-like unstable mode with front-to-rear vertical tilt. This tilted unstable mode produced stages of preconditioning and stratiform rain (Khouider and Majda 2008) and the amplification by top-heavy diabatic heating with upper warm anomaly of vertically tilted structure (Tulich et al. 2007). These coupling mechanisms are known as "gravity wave mode."

In contrast with the gravity wave mode, which is driven by dynamical aspects, Neelin and Yu (1994) derived another unstable mode based on moist convective adjustment and a scaling by a typical lifetime of convection. Sobel et al. (2001) derived a moisture wave that balanced with the background moisture gradient under a weak temperature gradient condition. This unstable mode is now referred to as "moisture mode." The theoretical framework of this mode was constructed by many previous studies (Fuchs and Raymond 2002, 2005, 2007; Sugiyama 2009a,b; Sobel and Maloney 2012; Raymond et al. 2015), and has been applied in the context of the Madden-Julian oscillation (MJO) (Sobel and Maloney 2013; Adames and Kim 2016) and convectively coupled equatorial Rossby waves (Fuchs-Stone et al. 2019). In the tropics, precipitation amounts exponentially increase as the column saturation fraction increases (Bretherton et al. 2004; Peters and Neelin 2006). Thus, this moisture mode indicates an aspect of connection between synoptic moisture field modification and convective activity. Wolding et al. (2020) have shown proportions of precipitation diagnosed from column saturation fraction. Rossby waves and MJO indicated large fraction of $80 \%$ and almost $100 \%$, respectively. Their larger fractions suggested a strong connection between precipitation and column moisture. On the other hand, Kelvin waves showed only 50\%. Gonzalez and Jiang (2019) well captured westward-propagating intraseasonal events and showed that they well correspond to the convectively coupled Rossby waves. They investigated their highly stacked structure and their strong connection to column moisture. Those previous studies claimed an importance of column moisture for convective coupling of Rossby waves, in contrast to that of adiabatically driven Kelvin waves.

Idealized numerical models suggested that these unstable modes indicate different coupling regimes. Sobel and Bretherton (2003) showed two distinct forced waves in a nonrotating configuration. One was faster propagating that corresponds to the gravity wave, and the other was more slowly propagating or almost stationary mode that is closely tied to moisture.
Raymond and Fuchs (2007) constructed a convective parameterization that is sensitive to buoyancy and column moisture, and two unstable modes also appeared. One had vertically tilted structure that is forced by buoyancy-based precipitation, and the other had a vertically stacked structure whose precipitation is mainly controlled by column moisture.

Recently, some analysis methodologies on zonal wavenumber-frequency space have been developed. Yasunaga and Mapes (2012a,b) showed different phase relations between column water vapor (CWV) and precipitation for divergent or rotational wave modes. Yasunaga et al. (2019) analyzed a columnintegrated moist static energy budget in the zonal wavenumberfrequency space and quantified each budget component's contributions to its time evolution. They interpreted the results as horizontal advection plays a main role for Rossby waves' propagation, and vertical advection plays a role for Kelvin waves' propagation. Inoue et al. (2020) defined the tilt ratio and topheaviness to represent various vertical motion structures and indicated vertically erect Rossby waves and tilting Kelvin waves. These results suggested two different coupling modes may be assigned to Rossby and Kelvin waves, respectively.

Both observational and theoretical studies strongly suggest that CCEWs and MJO can be categorized into two groups. These consist of a moisture mode group made up of MJO and equatorial Rossby waves, and a gravity wave group containing Kelvin waves, inertia-gravity waves, and mixed Rossbygravity waves, as categorizing by a ratio of adjustment time scale of gravity wave to that of moist convection (Adames et al. 2019). Furthermore, different features are found in each group. The moisture modes have slower phase speeds and its precipitation is mainly expressed as a function of column moisture (Wolding et al. 2020; Raymond and Fuchs 2007). In contrast, the gravity wave modes have faster phase speeds and more vertically tilted structures and are driven by buoyancy fluctuations. These contrasts strongly suggest that ensembles and evolutions of convective activity may differ, as also assumed by Yasunaga and Mapes (2012a,b), and Wolding et al. (2020).

Convective activity is difficult to estimate in numerical models and reanalysis data because we should be careful about its resolution and bias, and observations by spaceborne radar produce important dataset of precipitation characteristics. We utilize TRMM PR level 2 observations to quantify precipitation and associated apparent heat source, and aim to discuss quantitatively how convection interacts with wave disturbances and how convectively coupled mechanisms work, focusing on convectively coupled equatorial Kelvin waves and equatorial Rossby waves because of their contrasting natures.

In the present study, we define the equatorial wave phase using FFT of infrared brightness temperature $\left(T_{b}\right)$ and conduct composite analyses aimed at summarizing the features of synoptic disturbances of CCEWs. We also quantify precipitation and latent heating amounts, which are estimated in the TRMM data products (Iguchi et al. 2000; Shige et al. 2004, 2009; Takayabu and Tao 2020). In the accompanying paper, Part II, we define some indices that represent the characteristics of individual rainfall events, such as size, height, and a degree of organization. 
TABLE 1. Summary of information of wave filtering.

\begin{tabular}{|c|c|c|c|c|c|c|c|}
\hline & Wavenumber & Period & $\begin{array}{l}\text { Equivalent } \\
\text { depth }\end{array}$ & $\begin{array}{l}\text { Reference } \\
\text { latitude }\end{array}$ & $\underset{\text { points }}{\operatorname{Minimum}} T_{b}$ & $\begin{array}{l}\text { Autocorrelation } \\
\text { time scale }\end{array}$ & $\begin{array}{l}\text { Autocorrelation zonal } \\
\text { spatial scale }\end{array}$ \\
\hline Rossby & -5 to -2 & 12 to 48 days & 10 to $100 \mathrm{~m}$ & $10^{\circ} \mathrm{N}$ & 131517 & $135 \mathrm{~h}$ & $25^{\circ}$ \\
\hline Kelvin & 4 to 8 & 4 to 6 days & 10 to $100 \mathrm{~m}$ & $0^{\circ}$ & 110315 & $30 \mathrm{~h}$ & $15^{\circ}$ \\
\hline
\end{tabular}

\section{Data and methodology}

To define CCEW wave phase, we used the Cloud Archive User Service (CLAUS) dataset (Hodges et al. 2000) along with a globally merged infrared radiation dataset (Janowiak et al. 2001). This dataset has $0.5^{\circ} \times 0.5^{\circ}$ horizontal grid and 3-h temporal resolution and provides long-term consistent brightness temperature $\left(T_{b}\right)$ data. The detailed merging procedure and its validity are described in Dias et al. (2017).

The analysis period is from December 2001 to November 2014. In August 2001, the TRMM satellite experienced its altitude change to prolong its lifetime. Due to this operation, there is a gap of data quality, such as a sensitivity of radar reflectivity and spatial resolution. This selection of analysis period is to avoid this gap of data due to the altitude change.

Spectrum analysis is performed on $T_{b}$ to detect CCEW signals as in Wheeler and Kiladis (1999) at different reference latitude (cf. Table 1, and described later), and we applied the meridional running mean with overlapping windows of its width of $3^{\circ}$ before performing the Fourier transformation procedure. The zonal-time spectrum of the symmetric part is shown in Figs. $1 \mathrm{a}$ and $1 \mathrm{~b}$, and the filtering bands of zonal wavenumber, period, and dispersion curve to detect signals of Kelvin and Rossby waves are shown in Table 1 . We choose reference latitudes as the equator for Kelvin waves and as $10^{\circ} \mathrm{N}$ for Rossby waves to focus on latitudes where variances of filtered $T_{b}$ are zonally and climatologically large. The filtering bands are relatively narrower than that used in previous studies. Yasunaga and Mapes (2014) demonstrated that fast or slow propagating Kelvin waves may involve different mechanisms. Inoue et al. (2020) pointed out that high-frequency and low-frequency Kelvin waves may have different vertical structures. These studies imply that Kelvin waves with different temporal and/or spatial scales, may have some different interactions between wave activity and convection. Thus, we choose narrow filtering bands to focus on the spectral peak at around zonal wavenumber 6 and its period from 4 to 6 days (Fig. 1a).

We define the wave phase from $-\pi$ to $\pi$ based on the timezonal-filtered $T_{b}$ at the reference latitude globally and annually (cf. Table 1 ). The local minimum of the filtered $T_{b}$ beyond $-1 \sigma$ is assigned to the most convectively active point, and on the other hand the local maximum point beyond $+1 \sigma$ is assigned to the most convectively inactive point. For Kelvin
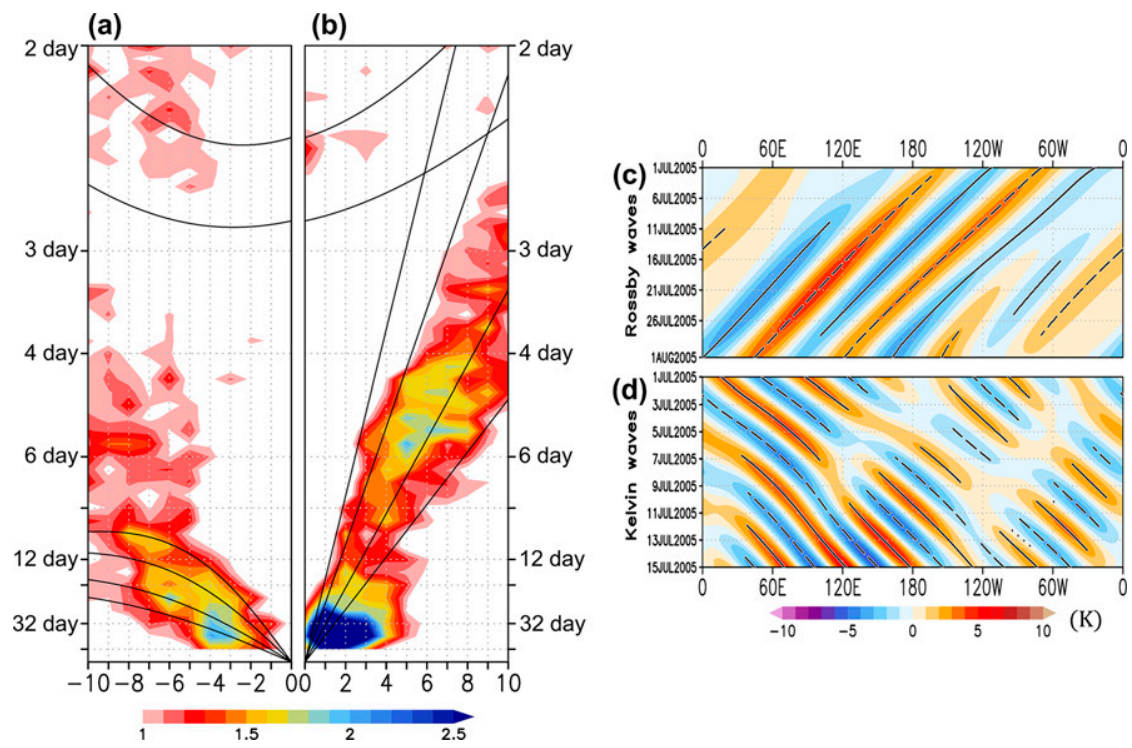

FIG. 1. Time-zonal power spectrum of the symmetric part of $T_{b}$ divided by its background red noise. (a) Westward spectrum at $10^{\circ} \mathrm{N}$ latitude and (b) eastward spectrum at the equator. Solid lines show dispersion curves of equatorial waves with 10,20,50, and $100 \mathrm{~m}$ of equivalent depth for Kelvin waves and Rossby waves and with 10 and $20 \mathrm{~m}$ for gravity waves. Hovmöller diagrams of filtered $T_{b}(\mathrm{~K})$ for (c) Rossby waves at $10^{\circ} \mathrm{N}$ latitude and (d) Kelvin waves at the equator. Solid lines indicate wave phase as $\pi / 2$ and dashed lines indicate wave phase as $-\pi / 2$. 


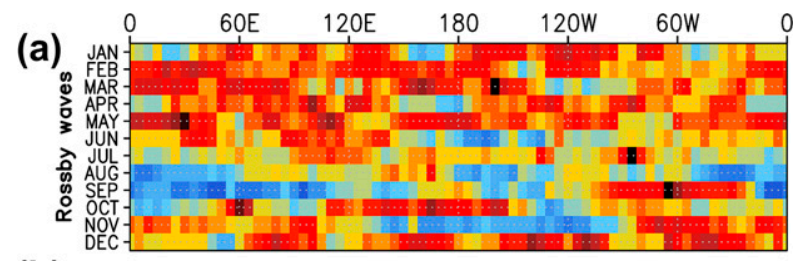

(b)

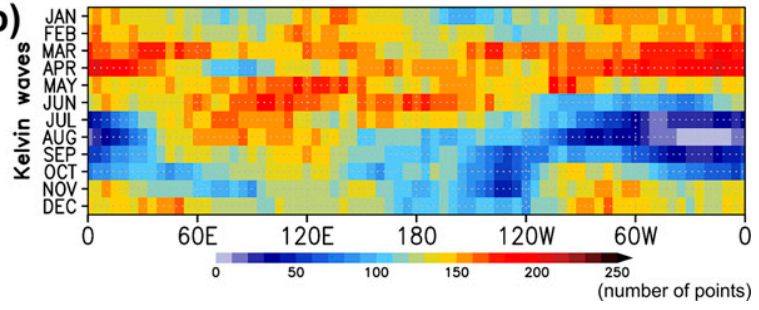

FIG. 2. Histogram of the zonal and seasonal distribution of number of minimum filtered $T_{b}$ points that is referred to as the most convectively active point for (a) Rossby waves and (b) Kelvin waves.

waves, the active point is set to phase $-\pi / 2$ and the inactive point is set to phase $\pi / 2$, but for Rossby waves the active point is set to phase $\pi / 2$ and the inactive point is set to phase $-\pi / 2$. This means that the following figures retain the actual westto-east direction. Therefore, Rossby waves propagate leftward and Kelvin waves propagate rightward, so that phase 0 corresponds to a phase with an increasing convective activity. We define the wave phase as the arcsine value of $T_{b}$ normalized by the nearest peak value. Figures $1 \mathrm{c}$ and $1 \mathrm{~d}$ show an example of a filtered $T_{b}$ and the convectively active and inactive points. The total number of minimum $T_{b}$ points at each reference latitudes that is lower than $-1 \sigma$ and assigned to convectively active point is summarized in Table 1 .

We then make a zonal and monthly histogram of the number of convectively active points. The Rossby wave occurrence frequency is higher from December to May and lower from July to October (Fig. 2a). Its zonal variability is relatively smaller than seasonal variability. The Kelvin wave occurrence frequency is remarkably higher in MAM and lower over the eastern Pacific Ocean and over the Atlantic Ocean in from June to October (Fig. 2b). The activity of convectively coupled Kelvin waves is known as strongly controlled by climatological variations of the sea surface temperature (Yang et al. 2003).

Next, we conduct composite analysis of synoptic-scale wave disturbances from December 2001 to November 2014 using the ERA5 dataset (Hersbach et al. 2020). For all variables, the time and zonal components of each data point are assigned to wave phase relative to filtered $T_{b}$ space. Thus, for the composite field, the $x$ axis is the wave phase, and the $y$ axis and $z$ axis are the latitude and pressure coordinates, respectively. To eliminate annual and seasonal change, we use anomalies from each year's 3-month seasonal average. We use ERA5 in 3-hourly temporal resolution to match that of $T_{b}$ dataset. Since the spatiotemporal resolution of ERA5 is notably smaller than that of CCEWs, we should restrict the degree of freedom for Student's $t$ test. We calculate the autocorrelation of filtered $T_{b}$. The time and distance at which autocorrelation reaches zero are summarized in Table 1. Here we conduct a nonzero Student's $t$ test on the anomalous composite whose degree of freedom is the number of composited points divided by the grid number in autocorrelation spatial scale. We should note that this approach preserves the information with respect to the sign of the anomaly, unlike a regression where both positive and negative perturbations contribute to the signal.

To investigate precipitation coupled with equatorial waves, we use the TRMM level 2 data products, 2A25 and 2H25 V7 (Iguchi et al. 2000; Shige et al. 2004, 2009; Takayabu and Tao 2020). Utilizing three-dimensional precipitation radar data, we define a rainfall-event as contiguous rainfall pixels with surface precipitation amounts greater than $0.5 \mathrm{~mm} \mathrm{~h}^{-1}$. The pixel which has the maximum surface precipitation amount in a rainfall event represents the event's date, time and location. Each rainfall event contains information on its location, date and time, sum of surface precipitation, and total vertical apparent heat source and moisture $\operatorname{sink}\left(Q_{1}-Q_{R}, Q_{2}\right.$; Yanai et al. 1973) which is estimated based on radar retrieval in TRMM $2 \mathrm{H} 25$ product. Composites of values belonging to rainfall events are defined as summations over rainfall events, which are classified into 32 wave phase bins, from $-\pi$ to $\pi$, and $2.5^{\circ}$ latitude grid, divided by total numbers of pixels observed by TRMM PR, instead of total numbers of rainfall events. Since we employ orbit data, TRMM level 2 products, which only produce inhomogeneous sampling, this normalization is equivalent to unconditional mean. Another composite for precipitation amount is meridional climatological mean, which is calculated in the same manner but using all rainfall events regardless of the wave phase bins with $2.5^{\circ}$ latitude grid. Then we carry out independent two sample Student's $t$ tests on the wave phase composite and meridional climatology on each latitude. Here we consider rainfall events as independent each other. Anomalous values of composite mean are defined as differences between wave phase composite and meridional climatology. We should note that rainfall events can depict detailed precipitation characteristics and this will be utilized in Part II.

For CWV and surface wind speed, we use gridded daily SSM/I dataset (Wentz et al. 2012). We regrid the dataset from its original grid interval of $0.25^{\circ}$ to $0.5^{\circ}$ to match the grid interval of $T_{b}$ and ERA5. The temporal resolution is once a day with time of data acquisition. We then conduct composite analyses and $t$ tests using same procedure as for the reanalysis data.

\section{Results}

\section{a. Disturbance structures and precipitation distributions}

In the composite horizontal structures (Fig. 3), it is confirmed that the horizontal wind anomaly and $T_{b}$ anomaly have equatorially symmetric structures for both waves. Because of the definition of the wave phase, the positive and negative maxima of $T_{b}$ anomalies are either at $+\pi / 2$ or at $-\pi / 2$. The positive vorticity centers of Rossby waves lead and 
(a)

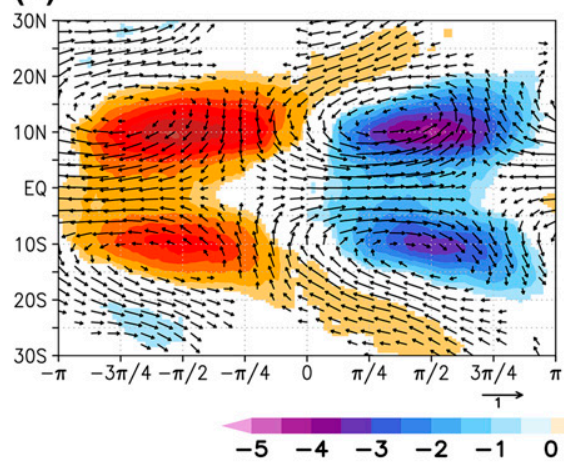

(b)

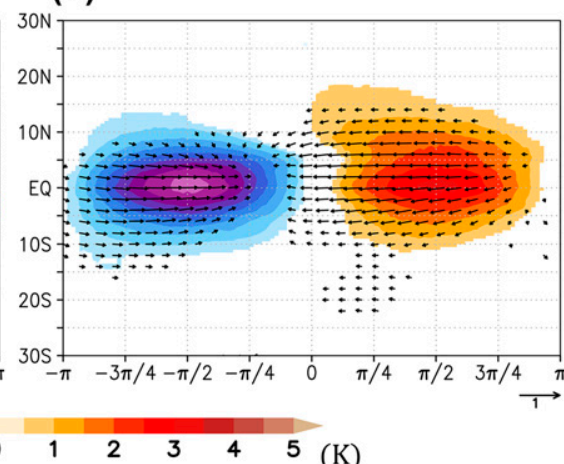

FIG. 3. Composite horizontal structures of brightness temperature anomalies (K; colors) and horizontal wind anomalies ( $\mathrm{m} \mathrm{s}^{-1}$; vectors) at $850 \mathrm{hPa}$ for (a) Rossby waves and (b) Kelvin waves. Shading for values over the $95 \%$ significance level and vectors whose zonal or meridional component meets the $95 \%$ significance levels are plotted.

lag the negative $T_{b}$ peak by about $\pi / 4$ (Fig. 3a). Amplitudes of vortical circulations and $T_{b}$ maximize almost in phase at $12^{\circ}-15^{\circ}$ and $10^{\circ}$, respectively. Some weak but robust $T_{b}$ anomalies also spread over the equator. In free-wave solution (Matsuno 1966), Rossby waves indicate that horizontal convergence lag behind cyclonic circulation by $1 / 4$ wavelength around off-equatorial region. Therefore, an importance of frictional convergence near the surface is suggested as discussed later. Kelvin waves (Fig. 3b), whose reference latitude is set to the equator, do not have meridional wind anomalies except near the center of horizontal convergence, which leads minimum $T_{b}$ by about $3 \pi / 8$. Amplitudes of zonal winds and $T_{b}$ are maximized on the equator. This symmetric pattern may be due to the global and annual composite and the choice of its reference latitude, whereas previous studies suggest that, for Kelvin waves, dynamical signals are more centered on the equator, while convection is located within the ITCZ over the Pacific Ocean (cf. Straub and Kiladis 2002; Takayabu and Murakami 1991; Takayabu et al. 1999). To investigate the relationship between convective activity and circulation, we choose references on the latitudes that are most convectively active based on the following results in vertical cross sections. These latitudes are $10^{\circ} \mathrm{N}$ for Rossby waves and the equator for Kelvin waves.

We next produce composite figures for precipitation and CWV based on satellite observations (Fig. 4). Anomalous values from the climatological unconditional mean indicate almost symmetric distributions of precipitation and CWV. Precipitation distributions are close to horizontal convergence predicted by free-wave characteristics and qualitatively consistent with the propagation characteristics shown in Lubis and Jacobi (2015). For Rossby waves, both positive and negative precipitation and CWV peaks clearly exist. The precipitation anomaly peak is at around $\pi / 4$, and CWV anomaly peak is behind $\pi / 2$. These two peaks lag about $1 / 8$ wavelength. Their amplitudes in the Northern Hemisphere are larger than in the Southern Hemisphere. In contrast, Kelvin waves show weak but substantial positive CWV anomaly around $-\pi / 2$, (a)

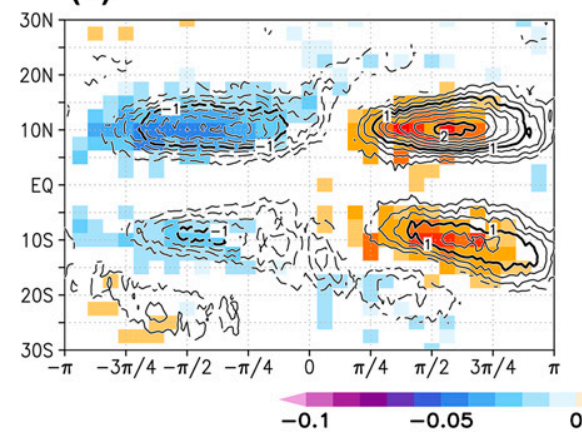

(b)

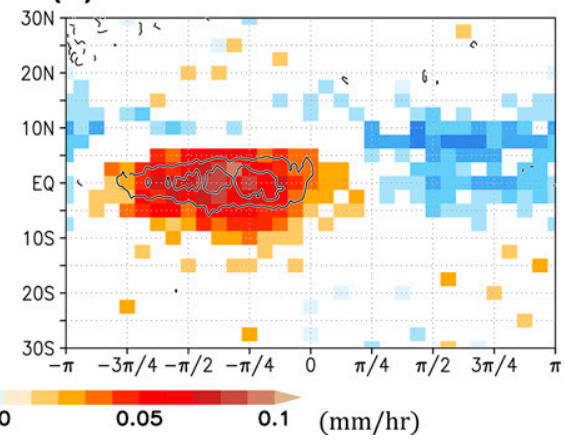

FIG. 4. Composite horizontal precipitation amount from rainfall events as the unconditional mean ( $\mathrm{mm} \mathrm{h}^{-1}$; colors) and CWV derived from SSM/I ( $\mathrm{mm}$; contours with intervals of $\left.0.2 \mathrm{~mm}\right)$ as anomalous values from climatology for (a) Rossby waves and (b) Kelvin waves. Grids and contours for values over the $95 \%$ significance levels are plotted. 
(a)

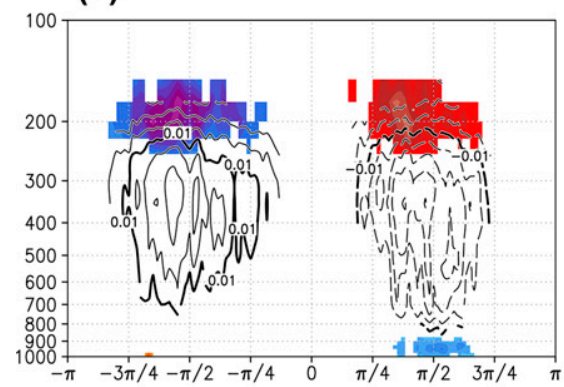

(b)

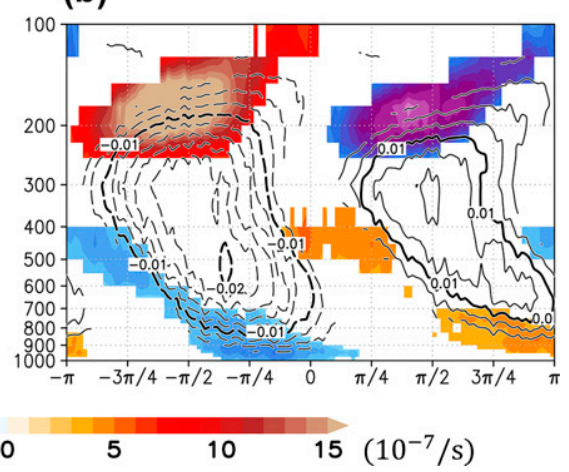

FIG. 5. Composite vertical structures of horizontal wind divergence $\mathrm{s}^{-1}$; colors) and pressure velocity anomalies $\left(\mathrm{Pa} \mathrm{s}^{-1}\right.$; contours with intervals of $0.002 \mathrm{~Pa} \mathrm{~s}^{-1}$ ) for Rossby waves at $10^{\circ} \mathrm{N}$ and (b) Kelvin waves at the equator. Shading and contours for values over the $95 \%$ significance levels are plotted.

but do not have clear negative CWV anomalies, with anomalous values close to zero or even slightly positive around $\pi / 2$, despite of the existence of negative precipitation anomalies. Weak but positive correlation between CWV and precipitation is confirmed especially in their positive anomalies. This feature is consistent with the absence of the spectrum peak of precipitable water (Roundy and Frank 2004). The positive precipitation anomaly maximum is found at $-\pi / 4$, leading negative $T_{b}$ anomaly with $1 / 8$ wavelength.

The vertical cross sections show distinct differences between Rossby and Kelvin waves; a vertically upright structure for Rossby waves and a vertically tilted structure for Kelvin waves (Fig. 5). The structures have been investigated by statistical studies as Kiladis and Wheeler (1995) and Gonzalez and Jiang (2019) for Rossby waves and Straub and Kiladis (2002) for Kelvin waves. We obtained consistent results with statistical analyses using more recent dataset. As for Rossby waves, in the phase of active convection, low-level convergence and upper-level divergence are in phase and the upward motion is dominant, and their signs are reverse in the less precipitating phase (Fig. 5a). The low-level divergence signals have only weak statistical significance and are found below $800 \mathrm{hPa}$, which suggests that the frictional convergence of rotational flow in the boundary layer is an important factor, since the free-wave solution showed that horizontal divergence is in quadrature with vortical circulations, not in phase. Horizontal winds show that upper-level signals do not correspond to the free-wave characteristics (Fig. 6a). The upper-level divergence can be considered as a response at the top of an ensemble of moist convection, such as deep cumulonimbi and cloud clusters. The low-level convergence signals are found in cyclonic circulations, and are inferred to be frictional (Fig. 6e).

For Kelvin waves, the vertical tilted structure consists of a leading convergence near the surface at $\pi / 4$ followed by a middle-level convergence and an upper-level divergence at $-3 \pi / 4$ to $-\pi / 2$ (Fig. 5 b). In the convectively active phase $(-\pi$ to 0 ), the horizontal convergence shifts upward and rearward in the lower troposphere, and vertical upwelling velocity grows deeper as wave phase progresses. This evolution of
Kelvin wave circulation make drastic transition of vertical structure of vertical motion. These characteristics are qualitatively consistent with those depicted in previous studies (e.g., Kiladis et al. 2009). It is confirmed that horizontal divergence signals are primary due to the zonal wind except for upper level (Figs. 6b,d,f). The off-equatorial wind anomalies remain significant in the upper and middle levels (Figs. 6b,d), which may reflect the interaction with the extratropics of Kelvin waves (Straub and Kiladis 2003).

\section{b. Vertical structures of thermodynamic and specific humidity}

Vertical cross sections of the temperature anomalies are shown in Fig. 7. In the Rossby waves case, a large anomaly is notable at $300 \mathrm{hPa}$, and signals with an opposite sign exist in the lower half (Fig. 7a). These signals are centered at $\pm \pi / 2$, and thus are all in phase with convective activity. The structures in the lower free troposphere differ from previous studies. Kiladis et al. (2009) analyzed a positive temperature anomaly at $850 \mathrm{hPa}$ and a negative anomaly at $700 \mathrm{hPa}$. In contrast, our results show two negative anomaly peaks at 800 and $600 \mathrm{hPa}$ centered at around $\pi / 4$ and $\pi / 2$, respectively. This inconsistency may be caused by differences in the composite method as well as the geographical distributions of the station of radiosonde observation by Kiladis et al. (2009).

Kelvin waves, on the other hand, have a vertically tilted structure (Fig. 7b). The temperature and omega anomalies indicate a nearly quadrature phase relationship at each level with some modifications with convection, thus Kelvin waves are strongly suggested to be assigned to the gravity wave mode. In lower layer from the $900-$ to 500 -hPa levels, ascending anomaly is modified to slightly lag behind expected gravity wave-like quadrature relationship of warm anomaly and in phase with near-surface convergence at around $\pi / 4$. In upper layer from the 500 - to $200-\mathrm{hPa}$ levels, ascending anomaly is modified at around $\pi / 2$ to be earlier than expected quadrature relationship. This modulation results in vertically deeper ascending that is tied to low-level horizontal convergence and that may be caused by convectively coupling. 
(a)

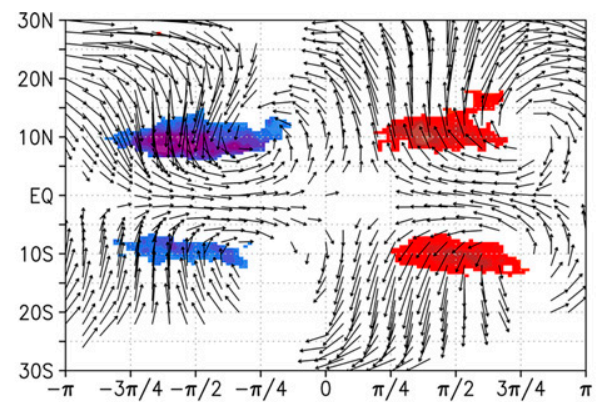

(c)

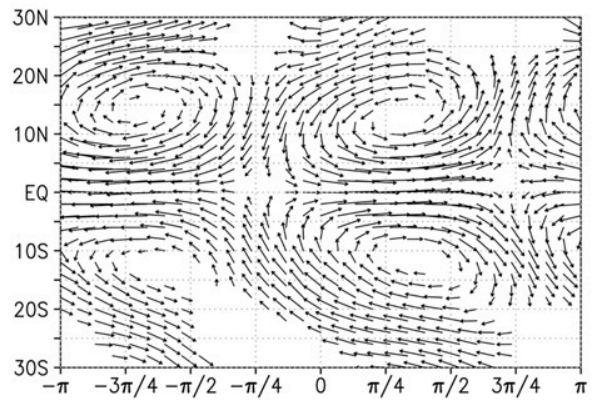

(e)

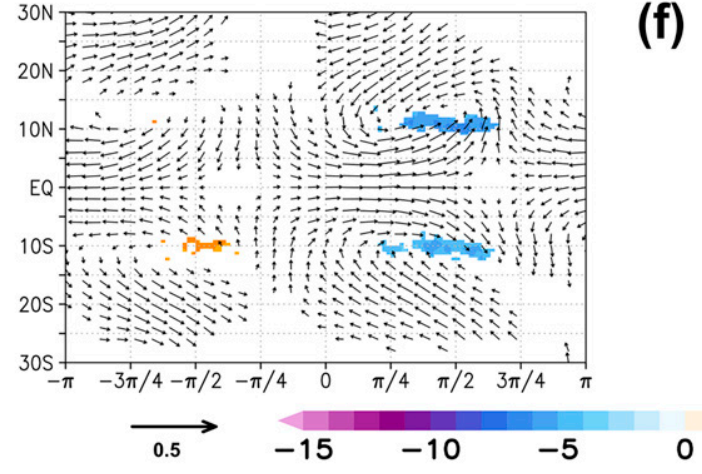

(b)

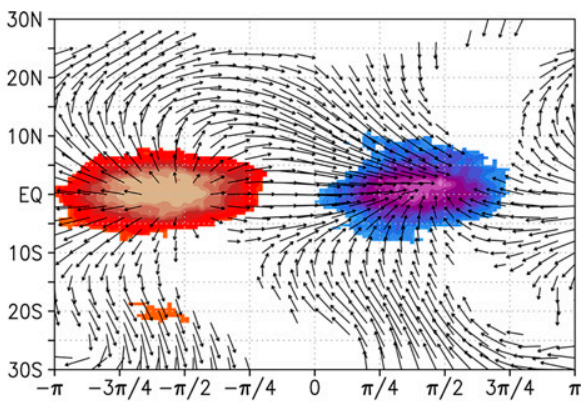

(d)
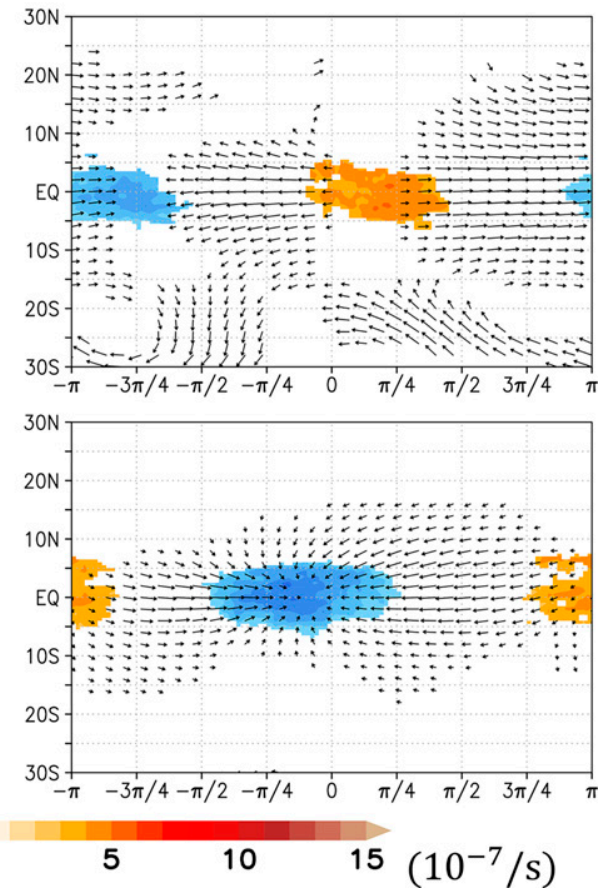

FIG. 6. Composite horizontal structures of horizontal wind ( $\mathrm{m} \mathrm{s}^{-1}$; vectors) and its divergence ( $\mathrm{s}^{-1}$; colors) at $200 \mathrm{hPa}$ for (a) Rossby waves and (b) Kelvin waves, at $500 \mathrm{hPa}$ for (c) Rossby waves and (d) Kelvin waves, and at $950 \mathrm{hPa}$ for (e) Rossby waves and (f) Kelvin waves. Shading for values over the $95 \%$ significance levels and vectors whose zonal or meridional component meets $95 \%$ significance levels are plotted. There is no significant shading in (c).

The vertical cross sections of composite specific humidity are shown in Fig. 8. Rossby waves again show a vertically upright structure (Fig. 8a). The moisture anomaly peaks slightly lag behind phase $\pm \pi / 2$ and the precipitation anomaly (Fig. 4a). Compared to a previous study (Kiladis et al. 2009), the peak in the free troposphere is found at a lower level while the peak near the surface is weaker. This may be caused by the difference of dataset: in situ observation and reanalysis. Since the synoptic condition with convergence at near surface, divergence in the upper troposphere, and a weak divergence around the middle troposphere (Figs. 6a,c,e), associated with deep upwelling motion (Fig. 5a) can moisten the free troposphere efficiently resulting CWV anomalies with large amplitude. When CWV shows a large positive anomaly, precipitation is encouraged (Bretherton et al. 2004; Peters and Neelin 2006). And on the other hand when a large negative anomaly is provided, precipitation is strongly suppressed. Thus the dipole-like large CWV anomalies strongly suggests that convectively coupled Rossby waves include a moisture mode driven by CWV variability as a coupling mechanism as suggested in Gonzalez and Jiang (2019).

For Kelvin waves, on the other hand, a vertically tilted specific humidity structure is found (Fig. 8b). The moist anomaly exists near the surface at the front side around $\pi / 2$, where downward motion is dominant in the free troposphere, and convection is inactive. When the horizontal convergence becomes dominant (Fig. 5b) and the upwelling motion starts developing at $\pi / 4$, the lower free troposphere becomes moist, but the middle level remains dry. Then the moist anomaly in the free troposphere spreads from the low troposphere to the middle troposphere as the wave phase progresses. In the largely precipitating phase around $-\pi / 2$ (Fig. $4 \mathrm{~b}$ ), the deep moist anomaly from the surface to the upper troposphere with the deep ascending is indicated. 
(a)

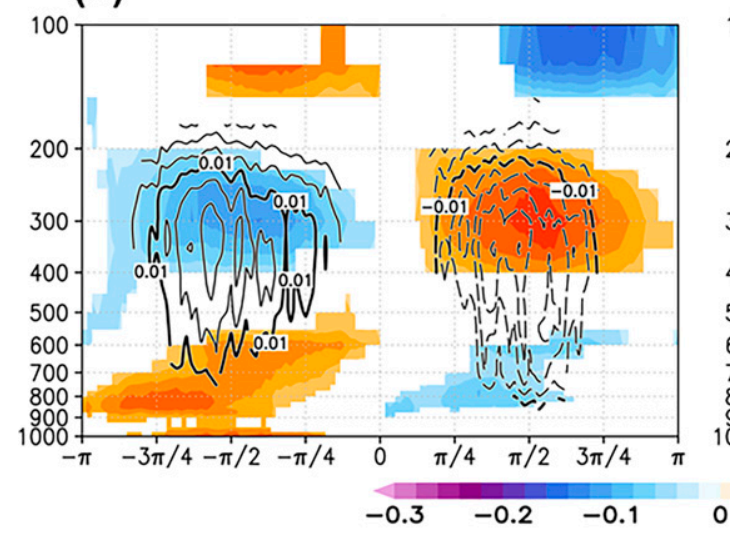

(b)

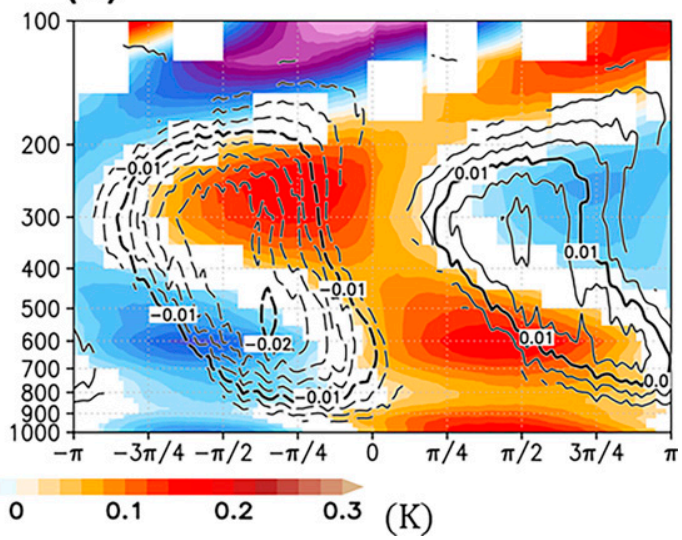

FIG. 7. Composite vertical structures of temperature anomalies (K; colors) and pressure velocity anomalies ( $\mathrm{Pa} \mathrm{s}^{-1}$; contours with intervals of $0.002 \mathrm{~Pa} \mathrm{~s}^{-1}$ ) for (a) Rossby waves at $10^{\circ} \mathrm{N}$ and (b) Kelvin waves at the equator. Shading and contours for values over the $95 \%$ significance levels are plotted.

\section{c. Heating profiles and budget analysis of column moist static energy}

Figure 9 shows the profile of apparent heat source (Yanai et al. 1973) minus radiative heating produced in the TRMM $2 \mathrm{H} 25$ product. The sign of anomalous heating in the Rossby waves (Fig. 9a) switches at 0 and $\pi$, which is consistent with the sign of the precipitation anomaly. This is mainly composed by top-heavy heating, whose peak is located around $400-\mathrm{hPa}$ level. The vertical profile of Kelvin wave heating anomaly transits from bottom-heavy into top-heavy (Fig. 9c) with larger amplitude than Rossby waves because of their larger positive precipitation anomalies (cf. Fig. 4). For both wave cases, the top-heavy heating is dominant in their maximum phase of precipitation and is in phase with upper-level anomalies of ascending and positive specific volume (Figs. $9 \mathrm{~b}, \mathrm{~d})$. Since top-heavy heating strongly indicates a dominance of organized convective systems (cf. Houze 1989; Schumacher et al. 2004) and the upper-level heating anomalies are almost synchronized with temperature anomalies (cf. Fig. 7), latent heat release from organized convection can generate available potential energy (APE) to drive and maintain wave disturbances via kinetic energy supply.

Next, we examine the column-integrated budget of moist static energy (MSE) as follows:

$$
\begin{aligned}
\left\langle\frac{\partial \bar{h}}{\partial t}\right\rangle+\left\langle\bar{u} \frac{\partial \bar{h}}{\partial x}\right\rangle+\left\langle\bar{v} \frac{\partial \bar{h}}{\partial y}\right\rangle+\left\langle\bar{\omega} \frac{\partial \bar{h}}{\partial p}\right\rangle & =H_{\mathrm{sfc}}+\left\langle Q_{R}\right\rangle-\left\langle\frac{\partial}{\partial p} \overline{\omega^{\prime} h^{\prime}}\right\rangle \\
& =\left\langle Q_{1}\right\rangle-\left\langle Q_{2}\right\rangle
\end{aligned}
$$

Here $h$ is MSE; $Q_{1}$ and $Q_{2}$ are the apparent heat source and moisture sink, respectively (Yanai et al. 1973); $Q_{R}$ is radiative heating; and $H_{\text {sfc }}$ is the surface heat flux, which includes sensible and latent heat. The angle brackets denote column integration from 1000 to $150 \mathrm{hPa}$. Above $150 \mathrm{hPa}$, wave structures might include stratospheric response (cf. Figs. 5 and 7). (a)

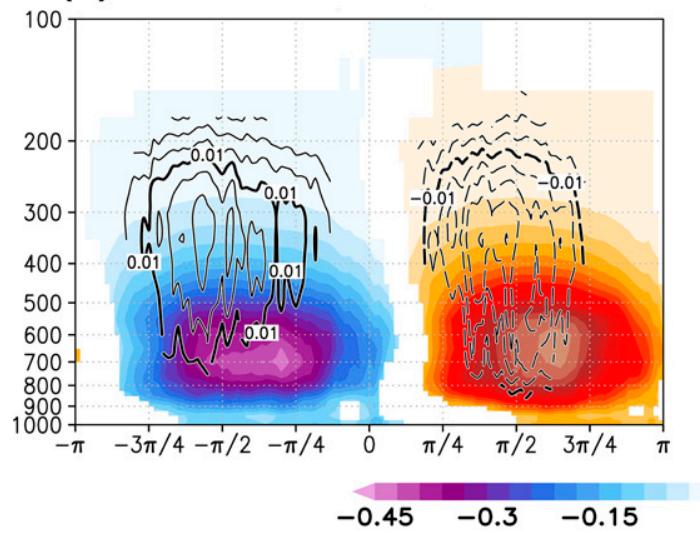

(b)

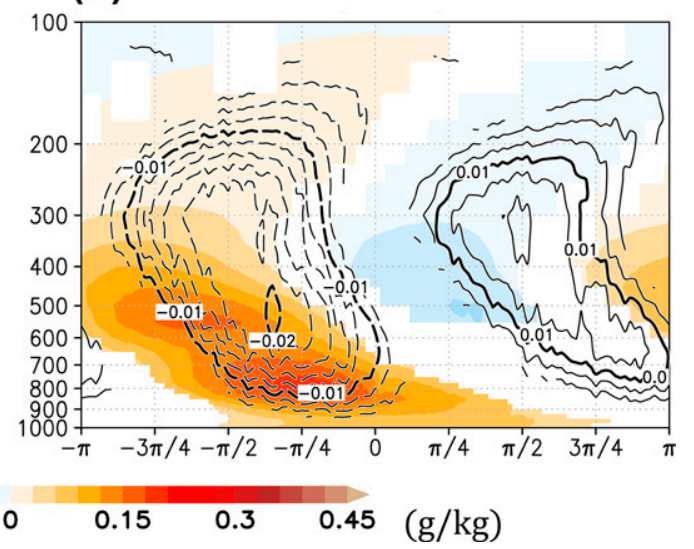

FIG. 8. Composite vertical structures of specific humidity anomalies $\left(\mathrm{g} \mathrm{kg}^{-1}\right.$; colors) and pressure velocity anomalies $\left(\mathrm{Pa} \mathrm{s}^{-1}\right.$; contours with intervals of $0.002 \mathrm{~Pa} \mathrm{~s}^{-1}$ ) for (a) Rossby waves at $10^{\circ} \mathrm{N}$ and (b) Kelvin waves at the equator. Shading and contours for values over the $95 \%$ significance levels are plotted. 
(a)

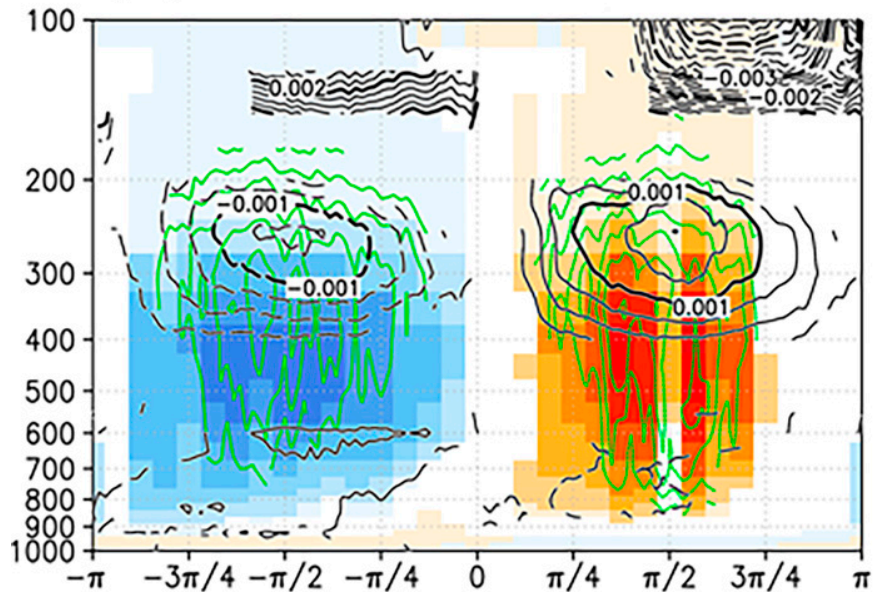

(c)
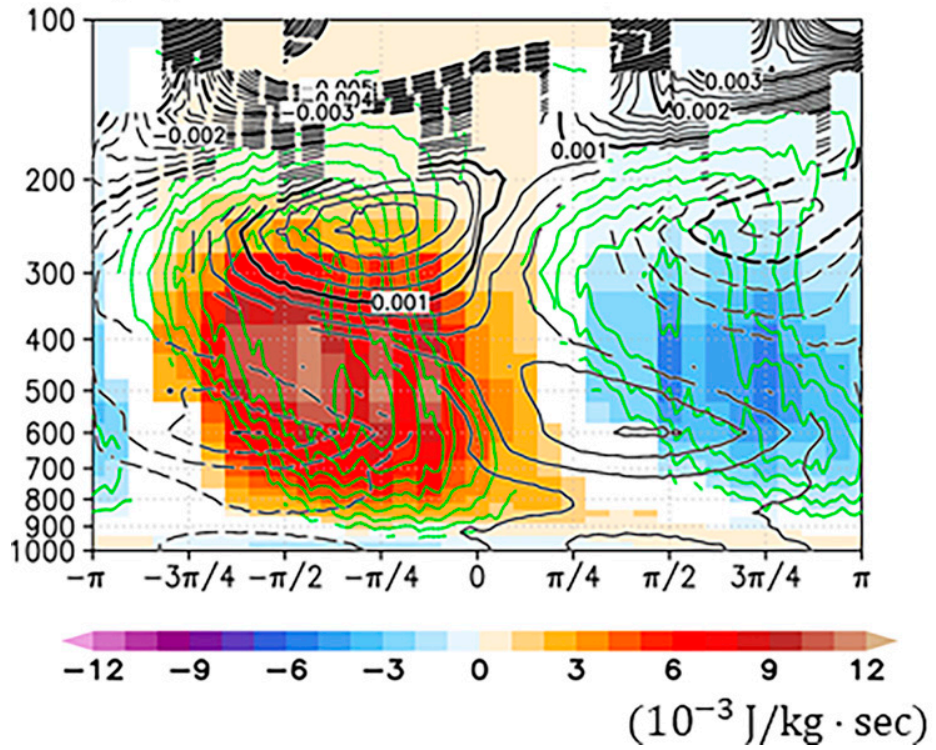

(b)

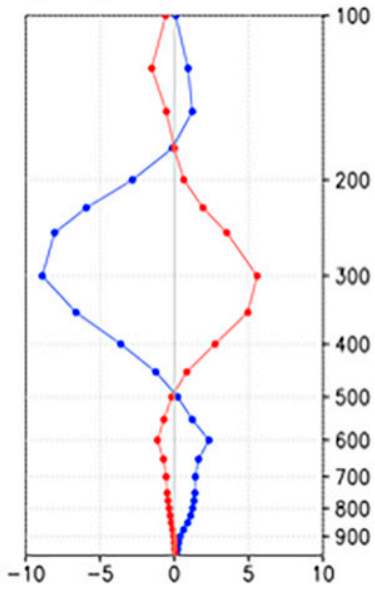

(d)

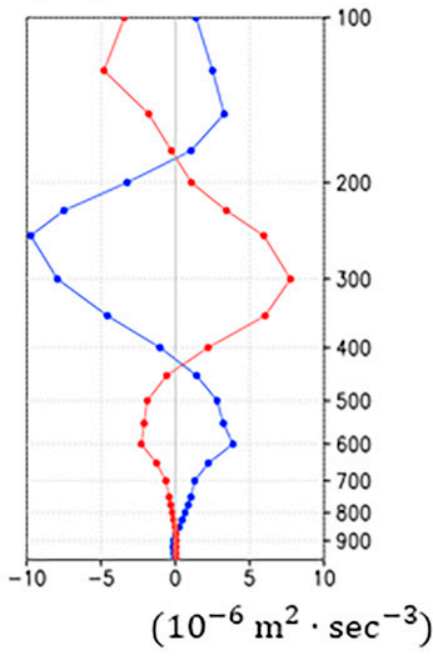

FIG. 9. Cross sections of composite of (a) estimated $Q_{1}-Q_{R}$ anomaly ( $\mathrm{J} \mathrm{kg}^{-1} \mathrm{~s}^{-1}$; colors) derived from the TRMM $2 \mathrm{H} 25$ product whose vertical coordinate is converted into pressure from height, specific volume anomaly $\left(\mathrm{m}^{3}\right.$ $\mathrm{kg}^{-1}$; black contours with intervals of $2 \times 10^{-4} \mathrm{~m}^{3} \mathrm{~kg}^{-1}$ ), and pressure velocity ( $\mathrm{Pa} \mathrm{s}{ }^{-1}$; green contours with intervals of $\left.0.002 \mathrm{~Pa} \mathrm{~s}^{-1}\right)$ for Rossby waves at $10^{\circ} \mathrm{N}$ and (b) vertical distribution of $\overline{\alpha^{\prime} \omega^{\prime}}$ (blue line) and $\left(R_{d} / p c_{p}\right) \overline{\alpha^{\prime} Q^{\prime}}$ (red line) for Rossby waves at $10^{\circ} \mathrm{N}$. (c),(d) As in (a) and (b), but for Kelvin waves at the equator. Shading and contours in (a) and (c) for values over the $95 \%$ significance levels are plotted.

The overbar denotes horizontal average and prime denotes deviation. Here, the scale of this horizontal average is the reanalysis grid, thus deviation means subgrid-scale processes. The horizontal divergence of cross terms, $\left\langle(\partial / \partial x) \overline{u^{\prime} h^{\prime}}\right\rangle$ and $\left\langle(\partial / \partial y) \overline{v^{\prime} h^{\prime}}\right\rangle$, are assumed to be smaller than the vertical counterpart and are omitted. The composite analysis of each term in the lhs, the tendency and advection terms, are calculated in the same way as other variables: we make a time series and seasonal mean and then make anomalous composites.
Additionally, surface heat flux and radiative heating are derived from the reanalysis dataset. The vertical convergence by vertical eddy transport is estimated from $\left\langle Q_{1}\right\rangle-\left\langle Q_{R}\right\rangle$ and $\left\langle Q_{2}\right\rangle$, which are estimated in the TRMM $2 \mathrm{H} 25$ product.

The MSE amplitude of Rossby waves is notably larger than that of Kelvin waves, while the precipitation amount amplitude is larger in the Kelvin waves case (Figs. 10a,b and 4). This larger amplitude of Rossby waves is largely due to moisture variance (cf. Figs. 7 and 8). That implies that Rossby 


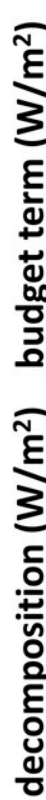

(a)

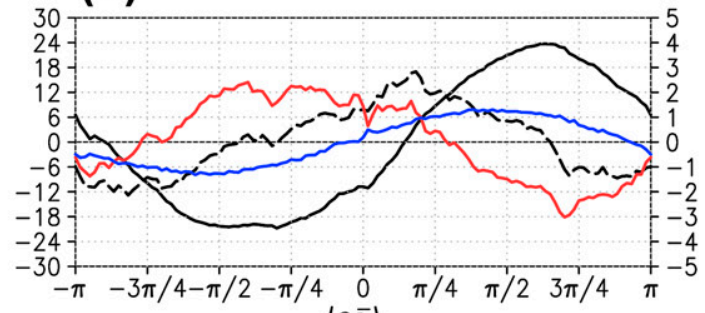

$-\mathbf{-}:\left(\frac{\partial \bar{h}}{\partial t}\right)$

(c)

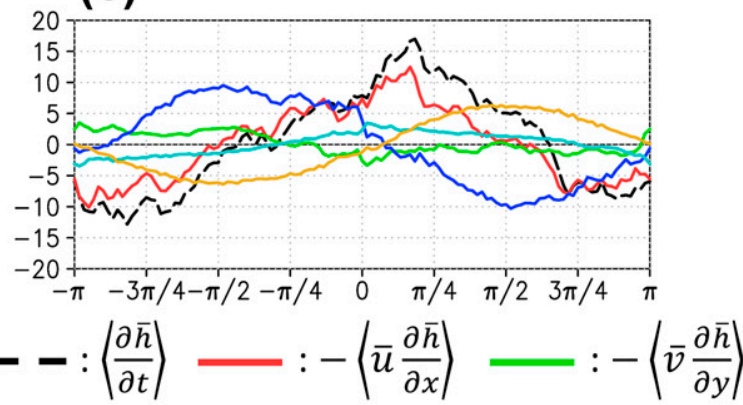

(e)

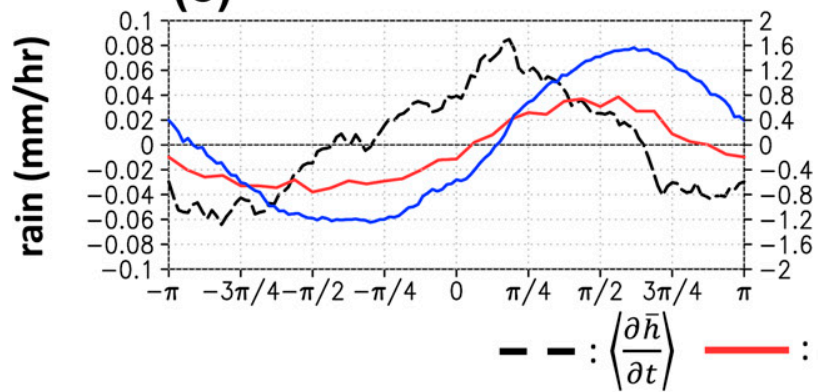

(g)

$\frac{\text { ำ }}{\frac{2}{3}}$

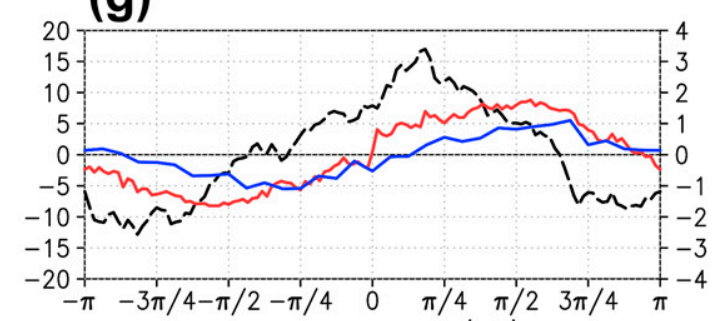

$--:\left(\frac{\partial \bar{n}}{\partial t}\right)-$ : residual (b)

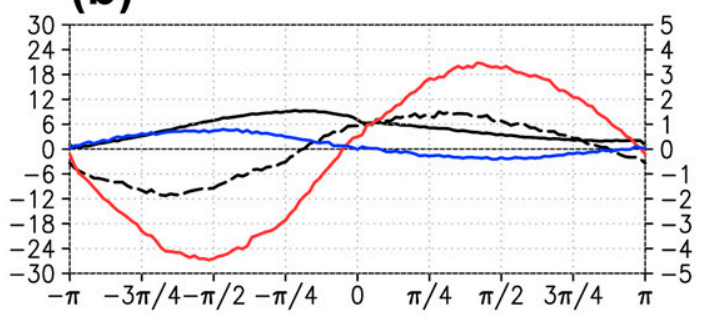

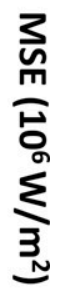

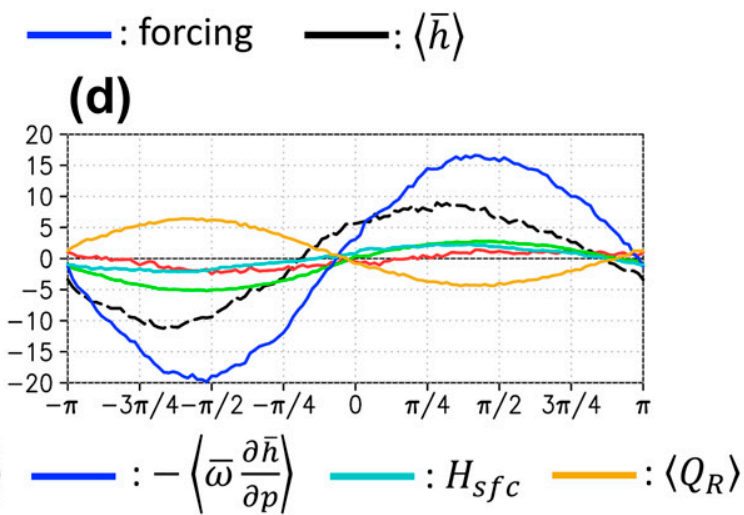

(f)

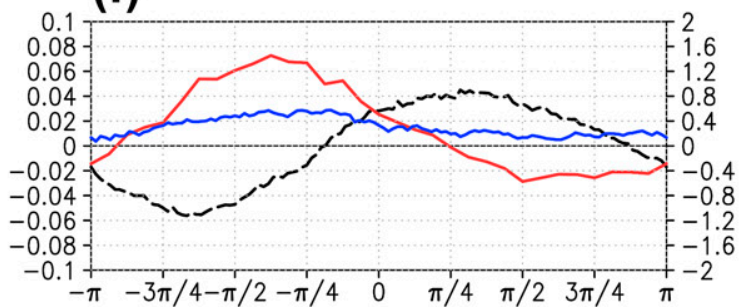

$\frac{\sum^{3}}{3}$

FIG. 10. Composite of column-integrated MSE budget anomalies. (a),(c),(e),(g) Rossby waves averaging from $5^{\circ}$ to $15^{\circ} \mathrm{N}$ and (b),(d),(f),(h) Kelvin waves averaging from $5^{\circ} \mathrm{S}$ to $5^{\circ} \mathrm{N}$. The bottom layer is $1000 \mathrm{hPa}$ and the top layer is $150 \mathrm{hPa}$ for column integration. The $y$ axis for the black dashed line in (e) and (f) are omitted. Legends of lines are below each row. All terms are calculated with ERA5, except for rain in (e) and (f) and $\left\langle Q_{1}\right\rangle-\left\langle Q_{2}\right\rangle-\left\langle Q_{R}\right\rangle$ in (g) and (h), which are obtained from TRMM PR, and CWV in (e) and (f), which is obtained from SSM/I. Details of terms are described in the text.

waves are strongly controlled by MSE and/or moisture modulation. To investigate how MSE fluctuation is formed, each term in Eq. (1) is decomposed; total advection term is $-\langle\bar{u}(\partial \bar{h} / \partial x)\rangle-\langle\bar{v}(\partial \bar{h} / \partial y)\rangle-\langle\bar{\omega}(\partial \bar{h} / \partial p)\rangle$ and forcing term is
$H_{\text {sfc }}+\left\langle Q_{R}\right\rangle$ in Figs. 10a and 10b, and each three advection terms, surface heat flux and radiative heating are in Figs. 10c and 10d.

In the Rossby waves case, the forcing term is almost in phase with MSE anomaly itself which indicates that forcing term 
TABLE 2. Estimated values of components for energy equations.

\begin{tabular}{|c|c|c|c|c|c|c|c|c|c|}
\hline & $\begin{array}{l}\int \frac{1}{2} W^{2} d x \\
\left(\mathrm{~kg}^{2} \mathrm{~m}^{-3}\right)\end{array}$ & $\begin{array}{c}-M_{\text {eff }} \int P W d x \\
\left(\mathrm{~kg}^{2} \mathrm{~m}^{-3} \mathrm{~s}^{-1}\right)\end{array}$ & $\begin{array}{c}\int E W d x \\
\left(\mathrm{~kg}^{2} \mathrm{~m}^{-3} \mathrm{~s}^{-1}\right)\end{array}$ & $\begin{array}{c}\left\langle\frac{1}{2}\left(\overline{u^{\prime 2}+v^{\prime 2}}\right)\right\rangle \\
\left(\mathrm{kg} \mathrm{s}^{-2}\right)\end{array}$ & $\left\langle\underset{\left(\mathrm{kg} \mathrm{s}^{-3}\right)}{-\frac{\partial}{\partial p} \overline{\phi^{\prime} \omega^{\prime}}}\right\rangle$ & $\left\langle\underset{\left(\mathrm{kg} \mathrm{s}^{-3}\right)}{-\frac{\partial}{\partial v} \overline{\phi^{\prime} v^{\prime}}}\right\rangle$ & $\begin{array}{r}\left\langle-\overline{\alpha^{\prime} \omega^{\prime}}\right\rangle \\
\left(\mathrm{kg} \mathrm{s}^{-3}\right)\end{array}$ & $\begin{array}{l}\left\langle\frac{1}{2 \sigma} \overline{\alpha^{\prime 2}}\right\rangle \\
\left(\mathrm{kg} \mathrm{s}^{-2}\right)\end{array}$ & $\begin{array}{c}\left\langle\frac{R_{d}}{p c_{p} \sigma} \overline{\alpha^{\prime} Q^{\prime}}\right\rangle \\
\left(\mathrm{kg} \mathrm{s}^{-3}\right)\end{array}$ \\
\hline Rossby & $5.14 \times 10^{6}$ & 6.22 & 2.00 & $9.56 \times 10^{2}$ & $-1.67 \times 10^{-3}$ & $-3.46 \times 10^{-3}$ & $7.60 \times 10^{-3}$ & $3.29 \times 10^{2}$ & $4.91 \times 10^{-3}$ \\
\hline Kelvin & $3.44 \times 10^{5}$ & 0.520 & -0.103 & $5.84 \times 10^{2}$ & $-3.75 \times 10^{-3}$ & $3.09 \times 10^{-3}$ & $3.68 \times 10^{-3}$ & $6.66 \times 10^{2}$ & $4.57 \times 10^{-3}$ \\
\hline
\end{tabular}

mostly contributes to amplification and maintenance rather than propagation (Fig. 10a), and this is mainly controlled by radiative heating (Fig. 10c). The total advection term damps MSE fluctuation, and this damping advection mainly consists of vertical advection (Fig. 10c). In the convectively active phase, upwelling plays a role in advection (Fig. 5a). Zonal advection is almost in phase with the tendency and meridional advection shows only weak contribution. This may be caused by large zonal gradient of MSE or CWV.

In the Kelvin waves case, on the other hand, the total advection term makes significant contributions to MSE propagation, whereas forcing terms are against propagation (Fig. 10b). The vertical advection shows a large amplitude whereas the horizontal advection is nearly zero (Fig. 10d). Kelvin waves have almost no meridional wind and small CWV gradient, thus the horizontal MSE advection is small. The vertical advection corresponds with a tilted omega structure.

In both Rossby waves and Kelvin waves, the maximum peaks of CWV lag to that of MSE tendency with $1 / 4$ wavelength (Figs. 10e,f), and MSE itself corresponds with CWV (cf. Figs. 10a,b). This indicates that MSE fluctuations tightly connect to CWV in both types of wave. However, their amplitudes are starkly different in each wave. Rossby waves show large MSE fluctuation and small precipitation perturbation. In contrast, Kelvin waves show small MSE fluctuation and large precipitation perturbation. This result strongly supports classifying Rossby waves as moisture mode and Kelvin waves as gravity wave mode. Precipitation coupled with Rossby waves is controlled by CWV and/or MSE, whereas precipitation coupled with Kelvin waves is controlled by buoyancy and/or dynamical disturbances.

Next, we quantify the amplitude of moisture mode and the generation of eddy APE and kinetic energy. According to the idealized description of moisture mode by Sobel and Maloney (2012), the growth of CWV is written as

$$
\frac{\partial}{\partial t} \int \frac{1}{2} W^{2} d x=-M_{\mathrm{eff}} \int P W d x+\int \frac{H_{\mathrm{lh}}}{L_{c}} W d x .
$$

Here $M_{\text {eff }}$ is effective gross moist stability, $W$ is CWV, $P$ is precipitation, $H_{\mathrm{lh}}$ is surface latent heat flux, and $L_{c}$ is latent heat of condensation. Integration is over one wavelength and the diffusion is neglected. The value for $M_{\text {eff }}$ is set to -0.1 for Rossby waves and -0.03 for Kelvin waves, which is calculated with ERA5 variables as a zonal and temporal mean of $(\langle\bar{u} \partial \bar{h} / \partial x\rangle+\langle\bar{v} \partial \bar{h} / \partial y\rangle+\langle\bar{\omega} \partial \bar{h} / \partial p\rangle) /\langle\bar{\omega} \partial \bar{s} / \partial p\rangle$ in our analysis period and at its reference latitude. Here the $s$ is dry static energy. This formulation implies the moisture mode is efficiently amplified when the anomalies of CWV and precipitation are closely in phase. Rossby waves indicate significantly large amplitude of CWV and high efficiency for its growth (Table 2). Rossby waves need 7.2 days at its growth rate to achieve mature amplitude, which is well short of Rossby waves' period. On the other hand, Kelvin waves show only slight CWV amplitude and quite weak amplification.

The growth as eddy disturbances are described as follows (cf. Nitta 1972):

$$
\begin{gathered}
\frac{\partial}{\partial t}\left\langle\frac{1}{2}\left(\overline{u^{\prime 2}}+\overline{v^{\prime 2}}\right)\right\rangle=-\frac{\partial}{\partial y}\left\langle\overline{\phi^{\prime} v^{\prime}}\right\rangle-\frac{\partial}{\partial p}\left\langle\overline{\phi^{\prime} \omega^{\prime}}\right\rangle-\left\langle\overline{\alpha^{\prime} \omega^{\prime}}\right\rangle \\
\frac{\partial}{\partial t}\left\langle\frac{1}{2 \sigma} \overline{\alpha^{\prime 2}}\right\rangle=\left\langle\overline{\alpha^{\prime} \omega^{\prime}}\right\rangle+\frac{R_{d}}{p c_{p} \sigma}\left\langle\overline{\alpha^{\prime} Q^{\prime}}\right\rangle
\end{gathered}
$$

For these equations, overbar denotes average over one zonal wavelength, and prime denotes deviations. The angle brackets denote column integration same as Eq. (1). The $\alpha$ is specific volume and the $\phi$ is geopotential. The $Q$ is latent heat, but $Q_{1}-$ $Q_{R}$ estimated in TRMM product is substituted here. The $R_{d}$ is gas constant for dry air, the $c_{p}$ is specific heat of dry air at constant pressure, and the $\sigma$ is static stability parameter as constant. The terms of energy exchange between background and disturbances are small, thus they are omitted in Eqs. (3) and (4). The APE is generated by $\left\langle\overline{\alpha^{\prime} Q^{\prime}}\right\rangle$ and converted to kinetic energy by $\left\langle\overline{\alpha^{\prime} \omega^{\prime}}\right\rangle$ into kinetic energy. Since the anomalies of $\alpha^{\prime}, \omega^{\prime}$, and top-heavy heating are in phase especially in the upper levels (Fig. 9), Both waves have large growth of kinetic energy (Table 2). Rossby waves need 4.5 day and Kelvin waves need 2.2 days to reach mature amplitude.

The eddy MSE convergence plus surface heat flux is estimated in two ways: as a residual of budget terms in ERA5 and TRMM $2 \mathrm{H} 25$ product as follows:

$$
\begin{aligned}
H_{\text {sfc }}-\left\langle\frac{\partial}{\partial p} \overline{\omega^{\prime} h^{\prime}}\right\rangle & =\left\langle\frac{\partial \bar{h}}{\partial t}\right\rangle+\left\langle\bar{u} \frac{\partial \bar{h}}{\partial x}\right\rangle+\left\langle\bar{v} \frac{\partial \bar{h}}{\partial y}\right\rangle+\left\langle\bar{\omega} \frac{\partial \bar{h}}{\partial p}\right\rangle-\left\langle Q_{R}\right\rangle \\
& =\left\langle Q_{1}\right\rangle-\left\langle Q_{2}\right\rangle-\left\langle Q_{R}\right\rangle
\end{aligned}
$$

Here $\langle\partial \bar{h} / \partial t\rangle+\langle\bar{u} \partial \bar{h} / \partial x\rangle+\langle\bar{v} \partial \bar{h} / \partial y\rangle+\langle\bar{\omega} \partial \bar{h} / \partial p\rangle-\left\langle Q_{R}\right\rangle$ is calculated in ERA5 and $\left\langle Q_{1}\right\rangle-\left\langle Q_{2}\right\rangle-\left\langle Q_{R}\right\rangle$ is from TRMM $2 \mathrm{H} 25$ product. Note that these two values are from different datasets. The calculation in ERA5 depend on synoptic-scale motion, moisture, and radiation. On the other hand, the calculation in the TRMM product includes cloud microphysics (cf. Takayabu and Tao 2020). Despite the difference of dataset, it is confirmed that these two values are almost in phase qualitatively less than $\pi / 4$ phase lag, although their amplitudes are 5 times different (Figs. 10g,h). There could be some factors for 
(a)

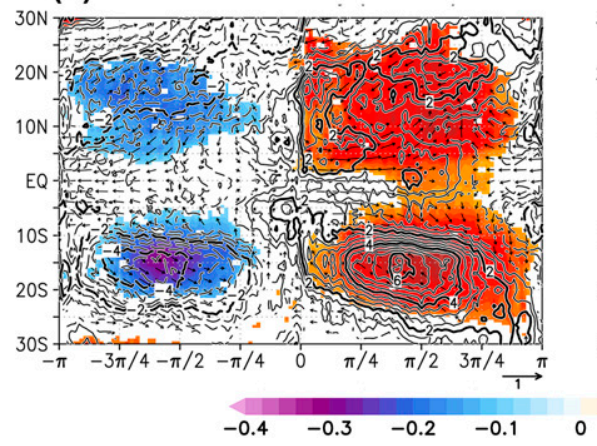

(b)

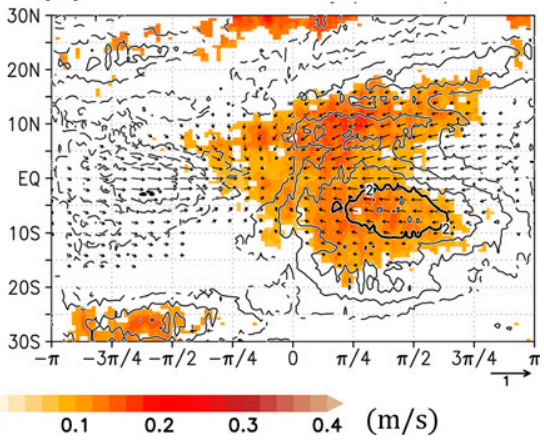

FIG. 11. Composite horizontal structures of horizontal wind speed anomalies derived from $\mathrm{SSM} / \mathrm{I}$ ( $\mathrm{m} \mathrm{s}^{-1}$; colors), surface latent heat flux estimated in ERA5 $\left(\mathrm{J} \mathrm{m}^{2} \mathrm{~s}^{-1}\right.$; contours with intervals of $0.5 \mathrm{~J} \mathrm{~m}^{2} \mathrm{~s}^{-1}$ ) and horizontal wind ( $\mathrm{m} \mathrm{s}^{-1}$; vectors) at $1000 \mathrm{hPa}$ in ERA5 for (a) Rossby waves and (b) Kelvin waves. Shading and contours for values over the $95 \%$ significance levels and vectors whose zonal or meridional component meets the $95 \%$ significance levels are plotted.

this large discrepancy, for example, differences in samplings. Above all, since convective activity is parameterized in the numerical model, there is no guarantee that eddy terms estimated with ERA5 represent quantitatively that of satellite observation estimates. This eddy term implies intensity of convective activity, therefore it is not surprised that it is in phase with precipitation anomaly. Another important implication is redistribution of MSE in vertical column. Though it is hard to make quantitative speculation here, this vertical eddy may resist about half of its damping via vertical advection.

To discuss the surface moisture flux, we conduct a composite analysis of surface wind speed using the SSM/I dataset. In the Rossby wave case (Fig. 11a), the anomalous composite of surface wind speed shows that high speed anomalies exist around the cyclonic flow, and low speed anomalies are found around anticyclonic flow. Latent heat release is concentrated in the convectively active region; thus, it may enforce only cyclonic circulations. Furthermore, the enhancement of surface latent heat flux around the cyclonic circulation with nearsurface convergence by cyclonic circulation (cf. Fig. 6f) can be a source of large amplitude of CWV. At the equator, there are no significant positive signals of easterly wind around phase $-\pi / 2$ although trade winds climatologically prevail. This implies the role of surface evaporation on westward propagation of large CWV may limited. In the Kelvin waves case (Fig. 11b), the surface wind is stronger in the easterly wind and horizontal convergence phase. This suggests that enhanced surface moisture flux by the preceding easterly overlapping climatological trade wind produces the leading moist anomaly near the surface. Additionally, moisture supplied from the surface in the convective inactive phase can compensate for the dry anomaly in the free troposphere (cf. Fig. 8b) and may cause a near-zero CWV anomaly.

\section{Summary and discussion}

In this study we define the wave phase of convectively coupled equatorial Rossby and Kelvin waves and conduct composite analyses of wave disturbances based on this wave phase. Furthermore, we quantify precipitation amount and CWV based on satellite observations. These findings are schematically shown in Fig. 12.

The vertically upright structure of the Rossby waves (Fig. 12a) induces the stacked column moisture. The frictional convergence by lower-level rotational flow (Figs. 5a and 6e) gathers the surface latent heat flux (Fig. 11a), and the deep ascending anomaly efficiently moisten the free troposphere (Fig. 8a), and they cause the column-integrated MSE with large amplitude. It is amplified by radiation, propagated by zonal advection, and damped by vertical advection. Precipitation anomaly is almost in phase with the CWV (Figs. 4a and 10e). This implies that convective activity can be activated with large CWV (Bretherton et al. 2004; Peters and Neelin 2006). The quite large amplitude of CWV and the high correlation between precipitation and CWV strongly suggest Rossby waves have moisture mode for its convectively coupled mechanism. Furthermore, since topheavy diabatic heating is in phase with upper positive temperature or specific volume (Figs. 7a and 9a,b), it is inferred that organized convective systems play a role for the generation of eddy APE and kinetic energy. This implies the propagation of moisture mode coupled with Rossby waves may be rooted in Rossby waves' own westward propagation, rather than a driving via surface moisture flux, which is not positive in front side (Fig. 11a).

The Kelvin waves have a vertically tilted structure (Fig. $12 \mathrm{~b}$ ) and its omega and temperature anomalies show nearly quadrature phase relationship (Fig. 7b), indicating the characteristics of the gravity wave. At $3 \pi / 4$, precipitation indicate a negative anomaly (Fig. 4b), but the near-surface layer is moist (Fig. 8b). At $\pi / 4$, the bottom-heavy heating starts to be positive (Fig. 9c), which implies either shallow cumulus or deep but isolated convection (cf. Houze 1989), and the wave disturbances show a shallow ascending anomaly, a moist lower free troposphere, and dry middle troposphere. At $-\pi / 4$, where precipitation reaches its maximum, top-heavy heating shows large positive anomaly, which implies a dominance of organized convection. The wave 
(a) Rossby waves

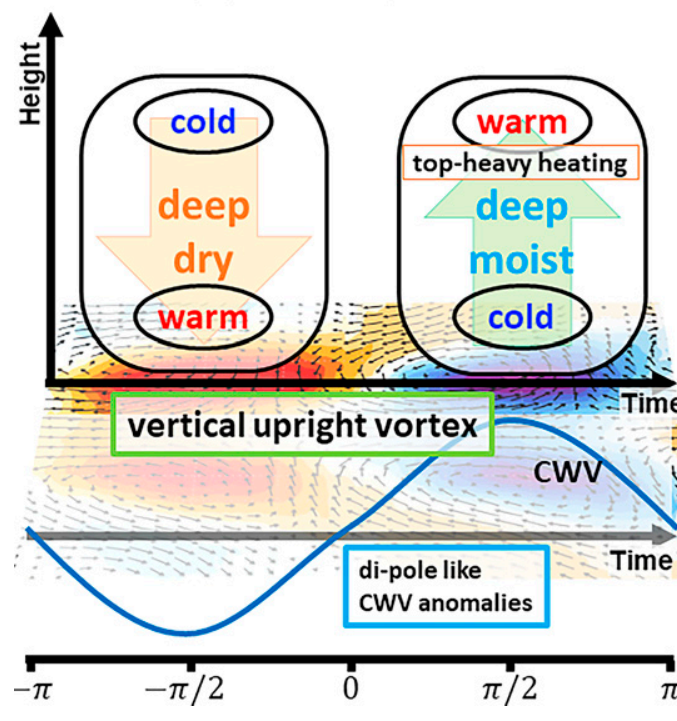

(b) Kelvin waves

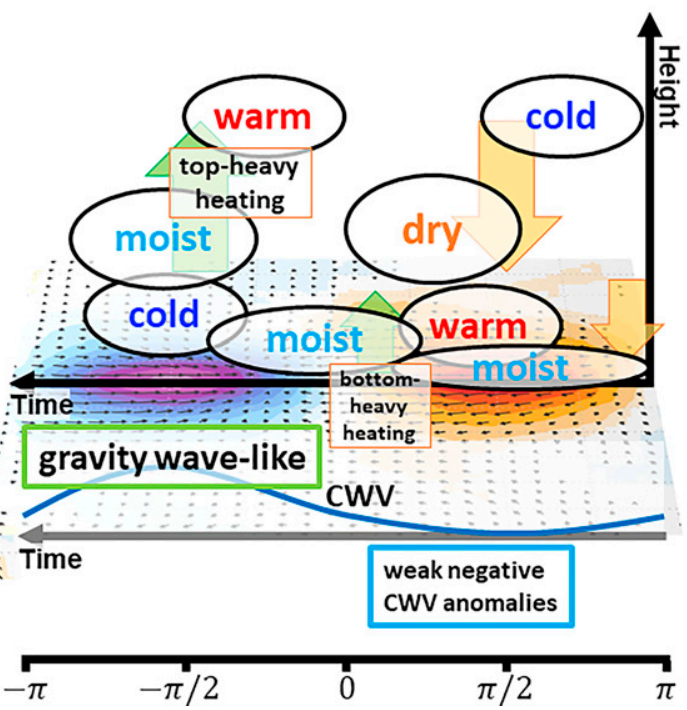

FIG. 12. Schematic figure of synoptic wave disturbances: humidity, temperature, vertical motion, and heating profile for (a) Rossby waves moving leftward and (b) Kelvin waves moving rightward.

disturbance at this phase indicates low-level horizontal convergence, deeply moist, and upper warm anomaly. These evolutions indicate strongly suggest Kelvin waves have gravity wave mode with eddy kinetic energy supply by MCSs and of the moist anomalies from near the surface to middle free troposphere. This coevolution between heating profile from bottom-heavy to top-heavy and the moist anomaly from the surface to midtroposphere may correspond to the moisture-stratiform instability proposed by Kuang (2008).

Meridional structure is more important for Rossby waves whereas Kelvin waves are confined to the equator and that seems intrinsic to its nature (cf. Kuang 2008). Furthermore, three-dimensional construction was required to produce theoretical unstable mode that corresponds to Rossby waves (cf. Fuchs-Stone et al. 2019). However, we focus on almost solely the most convectively active latitudes. There are some slightly positive precipitation anomalies at the equator even in the convectively inactive phase for Rossby waves. In Part II, we investigate and discuss precipitation characteristics of Rossby waves with its synoptic meridional structure.

Although we use global and annual reference signals of convectively coupled Rossby and Kelvin waves, previous studies indicate that propagation characteristics can differ seasonally and regionally (Yang et al. 2007a,b,c). In this study, we intend to detect more essential coupling characteristics and compare the results with previous idealized models. The methodology in this study implicitly assumes full propagation as a wave, which enables us to compare and test some ideas in simple models to actual situations. However, growing and decaying processes are not captured in the composite figure along the wave phase space. Another benefit of this methodology is that using many composite points enables us to investigate more directly convective activity using TRMM level 2 data products.
The free equatorial waves are derived as linearly separable. However, the total values of CWV and apparent heat source may be more important for convective activity, although we investigate anomalous values statistically in this study. Future work will require further discussions of this problem over a wide range of scales including the convective subgrid scale, the equatorial wave scale, and seasonal or longer climatological scales.

An issue of determination and commonality of equivalent depths of Rossby and Kelvin waves still remains. Results shown in the present study and previous idealized models strongly suggest that coupling modes of these two waves are quite different: Rossby waves correspond to moisture mode and Kelvin waves correspond to gravity wave mode. This difference cannot justify the commonality of equivalent depths. On the other hand, both waves are amplified by top-heavy heating via available potential energy generation (Fig. 9). Furthermore, both waves show vertically similar structure each other when heating is large: upper warm and lower cold, deeply moist, and topheavy omega (cf. Figs. 7 and 8). These similarities may support the commonality of equivalent depths, and we need further study and discussion.

Acknowledgments. The authors are grateful to Dr. George Kiladis, Prof. Adam Sobel, and an anonymous reviewer for their constructive comments that substantially helped to improve the presentation of this work. This study is supported by the Japan Aerospace Exploration Agency (JAXA) Precipitation Measuring Mission Science Program, the Environment Research and Technology Development Fund (JPMEERF 20192004) of the Environmental Restoration and Conservation Agency of Japan, and the University of Tokyo through a project called "Research hub for the big data analysis of global water cycle and precipitation in changing climate." 
Data availability statement. The ERA5 dataset that supports the findings of this study are available at https:/www.ecmwf.int/ en/forecasts/datasets/reanalysis-datasets/era5. The TRMM PR products $2 \mathrm{~A} 25$ and $2 \mathrm{H} 25$ that support the findings of this study are available at https:/gportal.jaxa.jp/gpr/index/index?lang=en. The daily SSM/I datasets that support the findings of this study are available at http://www.remss.com/missions/ssmi. If you need the dataset of brightness temperature that support wave phase determination, please contact the author(s).

\section{REFERENCES}

Adames, Á. F., and D. Kim, 2016: The MJO as a dispersive, convectively coupled moisture wave: Theory and observations. $J$. Atmos. Sci., 73, 913-941, https://doi.org/10.1175/JAS-D-150170.1

,-- , S. K. Clark, Y. Ming, and K. Inoue, 2019: Scale analysis of moist thermodynamics in a simple model and the relationship between moisture modes and gravity waves. $J$. Atmos. Sci., 76, 3863-3881, https://doi.org/10.1175/JAS-D-190121.1.

Bretherton, C. S., M. E. Peters, and L. E. Back, 2004: Relationships between water vapor path and precipitation over the tropical oceans. J. Climate, 17, 1517-1528, https://doi.org/10. 1175/1520-0442(2004)017<1517:RBWVPA > 2.0.CO;2.

Dias, J., N. Sakaeda, G. N. Kiladis, and K. Kikuchi, 2017: Influences of the MJO on the space-time organization of tropical convection. J. Geophys. Res. Atmos., 122, 8012-8032, https:// doi.org/10.1002/2017JD026526.

Fuchs, Ž., and D. J. Raymond, 2002: Large-scale modes of a nonrotating atmosphere with water vapor and cloud-radiation feedbacks. J. Atmos. Sci., 59, 1669-1679, https://doi.org/10. 1175/1520-0469(2002)059<1669:LSMOAN > 2.0.CO;2.

$\longrightarrow$, and - 2005: Large-scale modes in a rotating atmosphere with radiative-convective instability and WISHE. J. Atmos. Sci., 62, 4084-4094, https://doi.org/10.1175/JAS3582.1.

— , and — , 2007: A simple, vertically resolved model of tropical disturbances with a humidity closure. Tellus, 59A, 344-354, https://doi.org/10.1111/j.1600-0870.2007.00230.x.

Fuchs-Stone, Ž., D. J. Raymond, and S. Sentić, 2019: A simple model of convectively coupled equatorial Rossby waves. $J$. Adv. Model. Earth Syst., 11, 173-184, https://doi.org/10.1029/ 2018MS001433.

Gonzalez, A. O., and X. Jiang, 2019: Distinct propagation characteristics of intraseasonal variability over the tropical west Pacific. J. Geophys. Res. Atmos., 124, 5332-5351, https://doi. org/10.1029/2018JD029884.

Hayashi, Y.-Y., 1970: A theory of large-scale equatorial waves generated by condensation heat and accelerating the zonal wind. J. Meteor. Soc. Japan, 48, 140-160, https://doi.org/10. 2151/jmsj1965.48.2_140.

Hersbach, H., and Coauthors, 2020: The ERA5 global reanalysis. Quart. J. Roy. Meteor. Soc., 146, 1999-2049, https://doi.org/10. 1002/qj.3803.

Hodges, K. I., D. W. Chappell, G. J. Robinson, and G. Yang, 2000: An improved algorithm for generating global window brightness temperatures from multiple satellite infrared imagery. J. Atmos. Oceanic Technol., 17, 1296-1312, https://doi. org/10.1175/1520-0426(2000)017<1296:AIAFGG>2.0.CO;2.

Houze, R. A., 1989: Observed structure of mesoscale convective systems and implications for large-scale heating. Quart. J.
Roy. Meteor. Soc., 115, 425-461, https://doi.org/10.1002/qj. 49711548702.

Iguchi, T., T. Kozu, R. Meneghini, J. Awaka, and K. Okamoto, 2000: Rain-profiling algorithm for the TRMM Precipitation Radar. J. Appl. Meteor., 39, 2038-2052, https://doi.org/10. 1175/1520-0450(2001)040<2038:RPAFTT>2.0.CO;2.

Inoue, K., Á. F. Adames, and K. Yasunaga, 2020: Vertical velocity profiles in convectively coupled equatorial waves and MJO: New diagnoses of vertical velocity profiles in the wavenumber-frequency domain. J. Atmos. Sci., 77, 2139-2162, https:// doi.org/10.1175/JAS-D-19-0209.1.

Janowiak, J. E., R. J. Joyce, and Y. Yarosh, 2001: A real-time global half-hourly pixel-resolution infrared dataset and its applications. Bull. Amer. Meteor. Soc., 82, 205-218, https:// doi.org/10.1175/1520-0477(2001)082<0205:ARTGHH >2.3. $\mathrm{CO} ; 2$.

Johnson, R. H., T. M. Rickenbach, S. A. Rutledge, P. E. Ciesielski, and W. H. Schubert, 1999: Trimodal characteristics of tropical convection. J. Climate, 12, 2397-2418, https://doi.org/10.1175/ 1520-0442(1999)012<2397:TCOTC>2.0.CO;2.

Khouider, B., and A. J. Majda, 2006: A simple multicloud parameterization for convectively coupled tropical waves. Part I: Linear analysis. J. Atmos. Sci., 63, 1308-1323, https://doi.org/ 10.1175/JAS3677.1.

— , and — , 2007: A simple multicloud parameterization for convectively coupled tropical waves. Part II: Nonlinear simulations. J. Atmos. Sci., 64, 381-400, https://doi.org/10.1175/ JAS3833.1.

— , and - 2008: Equatorial convectively coupled waves in a simple multicloud model. J. Atmos. Sci., 65, 3376-3397, https://doi.org/10.1175/2008JAS2752.1.

Kiladis, G. N., and M. C. Wheeler, 1995: Horizontal and vertical structure of observed tropospheric equatorial Rossby waves. J. Geophys. Res., 100, 22981-22 997, https://doi.org/10.1029/ 95JD02415.

,-- , P. T. Haertel, K. H. Straub, and P. E. Roundy, 2009: Convectively coupled equatorial waves. Rev. Geophys., 47, RG2003, https://doi.org/10.1029/2008RG000266.

Kuang, Z., 2008: A moisture-stratiform instability for convectively coupled waves. J. Atmos. Sci., 65, 834-854, https://doi.org/10. 1175/2007JAS2444.1.

Liebmann, B., and H. H. Hendon, 1990: Synoptic-scale disturbances near the equator. J. Atmos. Sci., 47, 1463-1479, https://doi. org/10.1175/1520-0469(1990)047<1463:SSDNTE>2.0.CO;2.

Lindzen, R. S., 1974: Wave-CISK in the tropics. J. Atmos. Sci., 31, 156-179, https://doi.org/10.1175/1520-0469(1974)031<0156: WCITT>2.0.CO;2.

Lubis, S. W., and C. Jacobi, 2015: The modulating influence of convectively coupled equatorial waves (CCEWs) on the variability of tropical precipitation. Int. J. Climatol., 35, 1465-1483, https://doi.org/10.1002/joc.4069.

Mapes, B. E., 2000: Convective inhibition, subgrid-scale triggering energy, and stratiform instability in a toy tropical wave model. J. Atmos. Sci., 57, 1515-1535, https://doi.org/10.1175/ 1520-0469(2000)057<1515:CISSTE > 2.0.CO;2.

Matsuno, T., 1966: Quasi-geostrophic motions in the equatorial area. J. Meteor. Soc. Japan, 44, 25-43, https://doi.org/10.2151/ jmsj1965.44.1_25.

Matthews, A. J., and J. Lander, 1999: Physical and numerical contributions to the structure of Kelvin wave-CISK modes in a spectral transform model. J. Atmos. Sci., 56, 4050-4058, https://doi.org/10.1175/1520-0469(1999)056<4050:PANCTT> 2.0.CO;2. 
Neelin, J. D., and J. Yu, 1994: Modes of tropical variability under convective adjustment and the Madden-Julian Oscillation. Part I: Analytical theory. J. Atmos. Sci., 51, 1876-1894, https://doi.org/10.1175/1520-0469(1994)051<1876:MOTVUC> 2.0.CO;2.

Nitta, T., 1972: Energy budget of wave disturbances over the Marshall Islands during the years of 1956 and 1958. $J$. Meteor. Soc. Japan, 50, 71-84, https://doi.org/10.2151/jmsj1965. 50.2_71.

Peters, O., and J. Neelin, 2006: Critical phenomena in atmospheric precipitation. Nat. Phys., 2, 393-396, https://doi.org/10.1038/ nphys 314.

Raymond, D. J., and Ž. Fuchs, 2007: Convectively coupled gravity and moisture modes in a simple atmospheric model. Tellus, 59A, 627-640, https://doi.org/10.1111/j.1600-0870.2007.00268.x.

- - - S. Gjorgjievska, and S. Sessions, 2015: Balanced dynamics and convection in the tropical troposphere. J. $A d v$. Model. Earth Syst., 7, 1093-1116, https://doi.org/10.1002/ 2015MS000467.

Roundy, P. E., and W. M. Frank, 2004: A climatology of waves in the equatorial region. J. Atmos. Sci., 61, 2105-2132, https://doi. org/10.1175/1520-0469(2004)061<2105:ACOWIT > 2.0.CO;2.

Salby, M. L., and R. R. Garcia, 1987: Transient response to localized episodic heating in the tropics. Part I: Excitation and short-time near-field behavior. J. Atmos. Sci., 44, 458-498, https://doi.org/10.1175/1520-0469(1987)044<0458:TRTLEH> 2.0.CO;2.

Schumacher, C., R. A. Houze, and I. Kraucunas, 2004: The tropical dynamical response to latent heating estimates derived from the TRMM Precipitation Radar. J. Atmos. Sci., 61, 1341-1358, https://doi.org/10.1175/1520-0469(2004)061<1341: TTDRTL $>2.0 . \mathrm{CO} ; 2$

Shige, S., Y. N. Takayabu, W. Tao, and D. E. Johnson, 2004: Spectral retrieval of latent heating profiles from TRMM PR data. Part I: Development of a model-based algorithm. $J$. Appl. Meteor., 43, 1095-1113, https://doi.org/10.1175/15200450(2004)043<1095:SROLHP > 2.0.CO;2.

- - S. Kida, W. Tao, X. Zeng, C. Yokoyama, and T. L'Ecuyer, 2009: Spectral retrieval of latent heating profiles from TRMM PR data. Part IV: Comparisons of lookup tables from two- and three-dimensional cloud-resolving model simulations. J. Climate, 22, 5577-5594, https://doi.org/ 10.1175/2009JCLI2919.1.

Sobel, A., and C. S. Bretherton, 2003: Large-scale waves interacting with deep convection in idealized mesoscale model simulations. Tellus, 55A, 45-60, https://doi.org/10.3402/tellusa. v55i1.12084.

— , and E. Maloney, 2012: An idealized semi-empirical framework for modeling the Madden-Julian oscillation. J. Atmos. Sci., 69, 1691-1705, https://doi.org/10.1175/JAS-D-11-0118.1.

$\longrightarrow$, and - 2013: Moisture modes and the eastward propagation of the MJO. J. Atmos. Sci., 70, 187-192, https://doi.org/ 10.1175/JAS-D-12-0189.1.

—, J. Nilsson, and L. M. Polvani, 2001: The weak temperature gradient approximation and balanced tropical moisture waves. J. Atmos. Sci., 58, 3650-3665, https://doi.org/10.1175/ 1520-0469(2001)058<3650:TWTGAA > 2.0.CO;2.

Straub, K. H., and G. N. Kiladis, 2002: Observations of a convectively coupled Kelvin wave in the eastern Pacific ITCZ. J. Atmos. Sci., 59, 30-53, https://doi.org/10.1175/1520-0469 (2002)059<0030:OOACCK >2.0.CO;2.

, and - 2003: Extratropical forcing of convectively coupled Kelvin waves during austral winter. J. Atmos. Sci., 60,
526-543, https://doi.org/10.1175/1520-0469(2003)060<0526: EFOCCK $>2.0 . \mathrm{CO} ; 2$.

Sugiyama, M., 2009a: The moisture mode in the quasi-equilibrium tropical circulation model. Part I: Analysis based on the weak temperature gradient approximation. J. Atmos. Sci., 66 , 1507-1523, https://doi.org/10.1175/2008JAS2690.1.

— 2009b: The moisture mode in the quasi-equilibrium tropical circulation model. Part II: Nonlinear behavior on an equatorial $\beta$ plane. J. Atmos. Sci., 66, 1525-1542, https://doi.org/10. 1175/2008JAS2691.1.

Takayabu, Y. N., 1994: Large-scale cloud disturbances associated with equatorial waves. Part I: Spectral features of the cloud disturbances. J. Meteor. Soc. Japan, 72, 433-449, https://doi. org/10.2151/jmsj1965.72.3_433.

— , and M. Murakami, 1991: The structure of super cloud clusters observed in 1-20 June 1986 and their relationship to easterly waves. J. Meteor. Soc. Japan, 69, 105-125, https://doi. org/10.2151/jmsj1965.69.1_105.

— and W. K. Tao, 2020: Latent heating retrievals from satellite observations. Satellite Precipitation Measurement, V. Levizzani et al., Eds., Advances in Global Change Research Series, Vol. 69, Springer, https://doi.org/10.1007/978-3-03035798-6 22.

_- T. Iguchi, M. Kachi, A. Shibata, and H. Kanzawa, 1999: Abrupt termination of the 1997-98 El Niño in response to a Madden-Julian oscillation. Nature, 402, 279-282, https://doi. org/10.1038/46254.

Tulich, S. N., D. A. Randall, and B. E. Mapes, 2007: Verticalmode and cloud decomposition of large-scale convectively coupled gravity waves in a two-dimensional cloud-resolving model. J. Atmos. Sci., 64, 1210-1229, https://doi.org/10.1175/ JAS3884.1.

Wentz, F. J., K. A. Hilburn, and D. K. Smith, 2012: Remote sensing systems DMSP SSM/I daily environmental suite on 0.25 deg grid, version 7. Remote Sensing Systems.

Wheeler, M., and G. N. Kiladis, 1999: Convectively coupled equatorial waves: Analysis of clouds and temperature in the wavenumber-frequency domain. J. Atmos. Sci., 56, 374-399, https://doi.org/10.1175/1520-0469(1999)056<0374:CCEWAO > 2.0.CO;2.

Wolding, B., J. Dias, G. Kiladis, E. Maloney, and M. Branson, 2020: Interactions between moisture and tropical convection. Part II: The convective coupling of equatorial waves. $J$. Atmos. Sci., 77, 1801-1819, https://doi.org/10.1175/JAS-D-190226.1.

Yamasaki, M., 1969: Large-scale disturbances in a conditionally unstable atmosphere in low latitudes. Pap. Meteor. Geophys., 20, 289-336, https://doi.org/10.2467/mripapers1950. 20.4_289.

Yanai, M., S. Esbensen, and J. Chu, 1973: Determination of bulk properties of tropical cloud clusters from large-scale heat and moisture budgets. J. Atmos. Sci., 30, 611-627, https://doi.org/10.1175/1520-0469(1973)030<0611:DOBPOT> 2.0.CO;2.

Yang, G., B. Hoskins, and J. Slingo, 2003: Convectively coupled equatorial waves: A new methodology for identifying wave structures in observational data. J. Atmos. Sci., 60, 1637-1654, https://doi.org/10.1175/1520-0469(2003)060<1637:CCEWAN $>2$. $0 . \mathrm{CO} ; 2$.

,-- , and - , 2007a: Convectively coupled equatorial waves. Part I: Horizontal and vertical structures. J. Atmos. Sci., 64, 3406-3423, https://doi.org/10.1175/JAS4017.1. 
,-- , and,- 2007b: Convectively coupled equatorial waves. Part II: Propagation characteristics. J. Atmos. Sci., 64, 3424-3437, https://doi.org/10.1175/JAS4018.1.

$[,-$, and,$- 2007 \mathrm{c}$ : Convectively coupled equatorial waves. Part III: Synthesis structures and their forcing and evolution. J. Atmos. Sci., 64, 3438-3451, https://doi.org/10. 1175/JAS4019.1.

Yasunaga, K., and B. Mapes, 2012a: Differences between more divergent and more rotational types of convectively coupled equatorial waves. Part I: Space-time spectral analyses. $J$. Atmos. Sci., 69, 3-16, https://doi.org/10.1175/JAS-D-11-033.1.
— , and — , 2012b: Differences between more divergent and more rotational types of convectively coupled equatorial waves. Part II: Composite analysis based on space-time filtering. $J$. Atmos. Sci., 69, 17-34, https://doi.org/10.1175/JAS-D-11-034.1.

- , and — 2014: Differences between faster versus slower components of convectively coupled equatorial waves. $J$. Atmos. Sci., 71, 98-111, https://doi.org/10.1175/JAS-D-13-03.1. , S. Yokoi, K. Inoue, and B. E. Mapes, 2019: Space-time spectral analysis of the moist static energy budget equation. J. Climate, 32, 501-529, https://doi.org/10.1175/JCLI-D-180334.1. 